\title{
Review of ustekinumab, an interleukin-I 2 and interleukin-23 inhibitor used for the treatment of plaque psoriasis
}

This article was published in the following Dove Press journal:

Therapeutics and Clinical Risk Management

18 March 2010

Number of times this article has been viewed

\section{Nora Koutruba \\ Jason Emer \\ Mark Lebwohl}

Mount Sinai School of Medicine, New York, USA
Correspondence: Mark Lebwohl

Mount Sinai School of Medicine,

Chairman, Department of Dermatology,

5 East 98th Street, 5th Floor,

New York 10029, USA

Tel + | 2|2-24I-3288; + 2| 2-876-896 I

Email lebwohl@aol.com
Abstract: The pathogenesis of psoriasis is unknown, although it is generally accepted that this chronic inflammatory skin disorder is a complex autoimmune condition similar to other T-cell mediated disorders. Psoriasis imposes a heavy burden on the lifestyle of those affected due to the psychological, arthritic, and cutaneous morbidities; thus significant research has focused on the genetic and immunologic features of psoriasis in anticipation of more targeted, efficacious, and safe therapies. Recently, CD4 ${ }^{+} \mathrm{T}$ helper (Th) 17 cells and interleukins (IL)-12 and -23 have been important in the pathogenesis of T-cell mediated disorders such as psoriasis and has influenced the development of medications that specifically target these key immunological players. Ustekinumab is a monoclonal antibody belonging to a newly developed class of biological, anti-cytokine medications that notably targets the p40 subunit of both IL-12 and -23, both naturally occurring proteins that are important in regulating the immune system and are understood to play a role in immune-mediated inflammatory disorders. Ustekinumab's safety and efficacy has been evaluated for the treatment of moderate-to-severe plaque psoriasis in 3 phase III clinical trials, 2 placebo-controlled (PHOENIX 1 and 2), and 1 comparator-controlled (ACCEPT) study which proved advantageous in patients who were treatment-naive, previously failed other immunosuppressive medications including cyclosporine or methotrexate, were unresponsive to phototherapy, or were unable to use or tolerate other therapies. Ustekinumab has also been investigated for other indications such as psoriatic arthritis, Crohn's disease, and relapsing/remitting multiple sclerosis. We present a concise review evaluating the evidence that supports the use of ustekinumab in the treatment of plaque psoriasis and other conditions.

Keywords: ustekinumab, interleukin-12, interleukin-23, plaque psoriasis, biologics

\section{Introduction to management issues and role of ustekinumab}

Psoriasis is a chronic inflammatory disease characterized by well-circumscribed, erythematous plaques primarily affecting extensor skin surfaces due to an overproduction of basal keratinocytes. ${ }^{1}$ Moderate-to-severe cutaneous involvement can be burdening, as the condition can progress to cover a large body surface area including uncommon locations such as the hands and feet, genitals, and scalp. Symptoms of itching, burning, stinging, sensitivity, pain with associated bleeding, exudation, and skin scaling may be commonplace and cause difficulty sleeping, depression, and anxiety. ${ }^{2,3}$ About $10 \%$ to $30 \%$ of patients have associated psoriatic arthritis, a progressive, inflammatory arthropathy characterized by joint pain, swelling, and deformity; the frequency of psoriatic arthritis in persons with all types of psoriasis vary widely according to the nature of the diagnostic criteria, ascertainment used, 
and study population. ${ }^{4}$ Early detection and treatment is crucial, as this may block the further progression of joint damage. Classic joint symptoms such as swelling, warmth, and pain with associated restricted range of motion may limit work duties or daily activities which can significantly impair a person's quality of life. Conventional therapies for psoriatic arthritis include: non-steroidal anti-inflammatory medications (NSAIDs), systemic corticosteroids, diseasemodifying antirheumatic drugs (DMARDs) including methotrexate, sulfasalazine and/or leflunamide, and biological agents.

Ustekinumab (formerly CNTO 1275; Stelara $^{\mathrm{TM}}$; Centocor Inc., Horsham, PA, USA) is a newly developed, targeted monoclonal antibody directed against the common p40 subunit of interleukin (IL)-12 and IL-23; both are naturally occurring proteins that regulate specific components of the immune system. Both IL-12 and IL-23 have been associated with the pathogenesis of psoriasis, in part due to their relationship to the differentiation of naïve T-cells into Th1 and Th17 cells ${ }^{5,6}$

\section{IL-12}
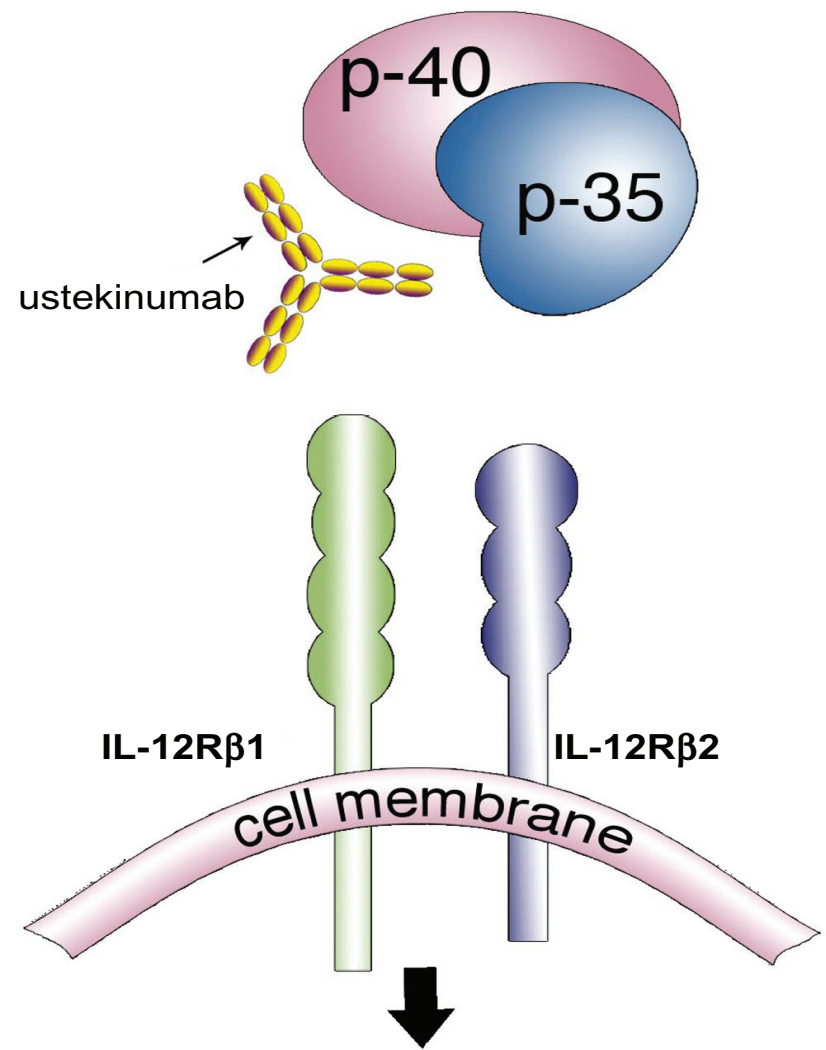

No Th 1 Signaling (TNF- $\alpha$, IFN- $\gamma$, IL-2)
(Figure 1). Th cells are a distinct subset of T-cells expressing unique characteristic cytokines each involved in mediating specific immune responses. As a newly developed, targeted biological agent, ustekinumab has demonstrated superior efficacy and safety in the treatment of plaque psoriasis by its unique mechanism of inhibiting IL-12/23 inflammatory pathways. ${ }^{7}$ IL-23 stimulates survival and proliferation of Th17 cells, a key cell that regulates the production of other inflammatory cytokines (IL-17, IL-22, IL-21, IL-6, tumor necrosis factor (TNF)- $\alpha$ ) and is overproduced in dendritic cells and keratinocytes found psoriatic plaques. ${ }^{8,9}$ Th1 cells develop from naïve T-cells after exposure to IL-12, characteristically express the transcription growth factor (TGF)- $\beta$, and are defined by a specific set of proinflammatory cytokines they produce (interferon(IFN)- $\gamma$, TNF- $\alpha$, IL-2).${ }^{10}$ It is becoming clearer that psoriasis is primarily due to a complex interaction of particular immune cells and inflammatory cytokines, with Th17 cells and IL-12 and IL-23 playing a critical role. Understanding of these immune

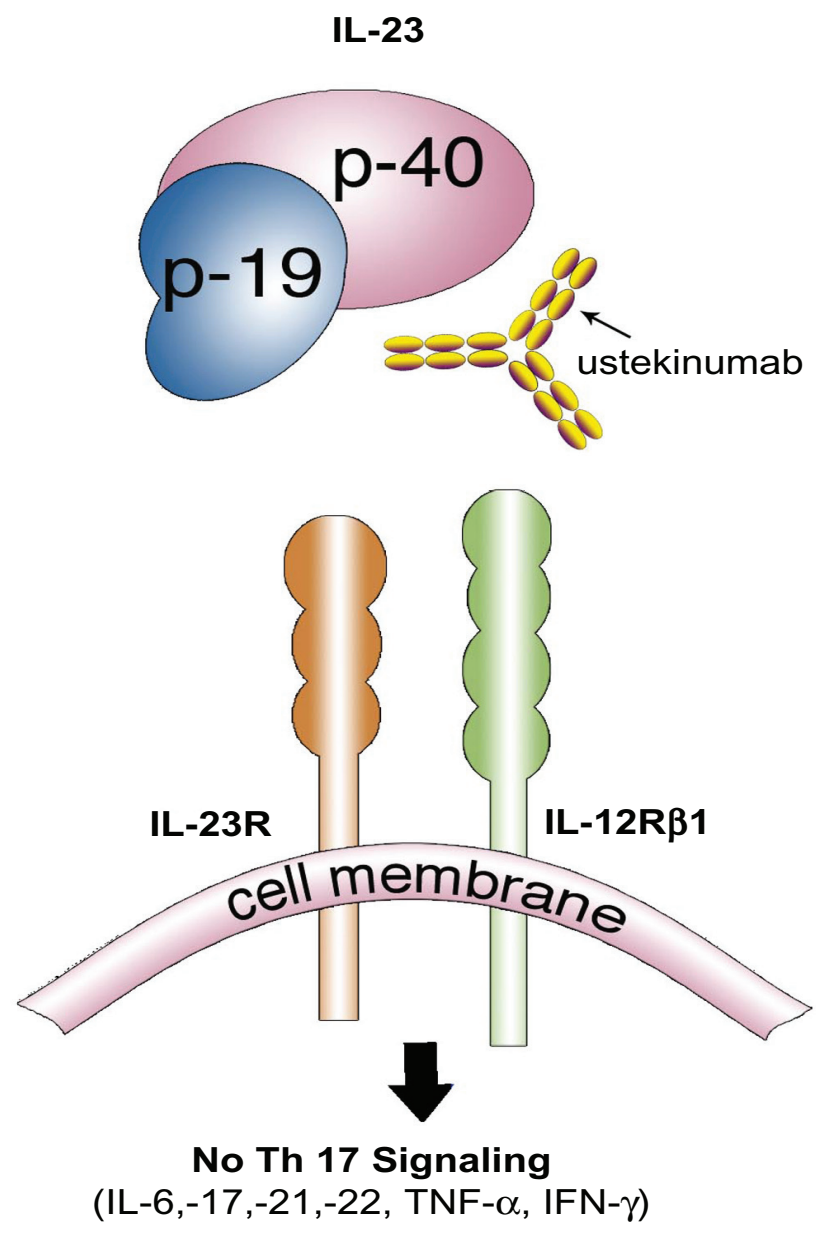

Figure I Ustekinumab, a human monoclonal antibody, works by inhibiting the similar p40 subunit of the proteins IL-I 2 and IL-23. Both IL- I 2 and IL-23 proteins are necessary to activate a cascade of inflammatory mediators responsible in the pathogenesis of psoriasis. Ustekinumab's inhibition of the IL-I2/23 pathway produces a profound suppression of both the ThI and ThI7 cell lineage of cytokines and chemokines resulting in a dramatic clearance of psoriasis. 
cascade complexities may influence how we treat T-cell influenced inflammatory conditions, such as psoriasis, in the future. In recent years, biologics have changed the treatment of psoriasis, giving dermatologists additional therapeutic options that are potentially less toxic to the liver, kidneys, and bone marrow, and are not teratogenic compared to the traditional systemic therapies for psoriasis (acitretin, methotrexate, and cyclosporine). Nevertheless, traditional systemic therapies continue to play an important role in the treatment of psoriasis with their oral route of administration and low cost (compared with biologics) making them an important treatment option in the appropriate patient. A physician with notable experience is needed for all systemic therapies used to treat psoriasis, as they necessitate patient education, frequent laboratory testing and monitoring, and regular office visits. Phototherapy is very efficacious, but requires a heavy time commitment, a phototherapy unit, may increase the risk of skin cancer, and involves the diligence of a physician who has experience making frequent use of this therapy. Those who are unable to tolerate conventional therapies or who have failed other treatments will be of the highest necessity for more safe and effective treatments. Newly developed biological agents such as ustekinumab have grown increasingly popular for the treatment of moderate-to-severe disease, as clinical studies have shown these agents to be free of the major organ toxicities of methotrexate and cyclosporine, and successful in treating those who may have been unresponsive or unable to tolerate traditional therapies (Table 1). Still, the biological agents have specific contraindications and potential side effects, as these medications are inherently immunosuppressive and long-term efficacy and safety is still relatively unknown. Ustekinumab was recently approved in the United States (September 2009) for the treatment of moderate-to-severe plaque psoriasis, and has already been marketed in Canada (December 2008) and Europe (January 2009). Ustekinumab has also been evaluated for its role in treating psoriatic arthritis, Crohn's disease, and RRMS. Any condition whose pathogenesis involves the IL-12/23 pathways has the potential to respond to treatment with this medication.

Table I Biological agents available for the treatment of psoriasis

\begin{tabular}{|c|c|c|c|c|c|c|}
\hline & Generic name & Trade name & Description & Dosing & $\begin{array}{l}\text { Other } \\
\text { indications }\end{array}$ & $\begin{array}{l}\text { Year of } \\
\text { United States } \\
\text { approval }\end{array}$ \\
\hline \multicolumn{7}{|l|}{ Anti-TNF- $\alpha$ agents } \\
\hline & Etanercept & Enbrel ${ }^{71}$ & $\begin{array}{l}\text { Dimeric fusion } \\
\text { protein }\end{array}$ & $\begin{array}{l}50 \mathrm{mg} \text { SC BIW for } 3 \text { months, } \\
\text { followed by a reduction to a } \\
\text { maintenance dose of } 50 \mathrm{mg} \\
\text { SC per week }\end{array}$ & $\begin{array}{l}\text { RA, JIA, } \\
\text { PsA, AS }\end{array}$ & 2004 \\
\hline & Adalimumab & Humira $^{72}$ & $\begin{array}{l}\text { Human monoclonal } \\
\text { antibody }\end{array}$ & $\begin{array}{l}80 \mathrm{mg} \mathrm{SC} \times \mathrm{I}, \text { followed by } \\
40 \mathrm{mg} \text { SC EOW starting } \\
\text { one week after initial dosage }\end{array}$ & $\begin{array}{l}\text { RA, JIA, PsA, } \\
\text { AS, CD }\end{array}$ & 2008 \\
\hline & Infliximab & Remicaide $^{73}$ & $\begin{array}{l}\text { Chimeric monoclonal } \\
\text { antibody }\end{array}$ & $\begin{array}{l}5 \mathrm{mg} / \mathrm{kg} \text { given as an IV } \\
\text { infusion, followed by } \\
\text { additional doses at } 2 \text { and } 6 \\
\text { weeks after the first infusion, } \\
\text { then every } 8 \text { weeks thereafter }\end{array}$ & $\begin{array}{l}\text { RA, CD, PsA, } \\
A S, \cup C\end{array}$ & 2006 \\
\hline \multicolumn{7}{|l|}{ Anti-T-cell agents } \\
\hline & Alefacept & Amevive $^{74}$ & $\begin{array}{l}\text { Dimeric fusion } \\
\text { protein }\end{array}$ & $\begin{array}{l}15 \mathrm{mg} \text { IM given once weekly } \\
\text { for } 12 \text { weekly injections }\end{array}$ & None & 2003 \\
\hline \multicolumn{7}{|l|}{$\begin{array}{l}\text { Anti-cytokine } \\
\text { agents }\end{array}$} \\
\hline & Ustekinumab & Stelara ${ }^{68}$ & $\begin{array}{l}\text { Human monoclonal } \\
\text { antibody }\end{array}$ & $\begin{array}{l}45 \mathrm{mg} \text { (if patient }<100 \mathrm{~kg} \text { ) } \\
\text { or } 90 \mathrm{mg} \text { (if patient }>100 \mathrm{~kg} \text { ) } \\
\mathrm{SC} \times \mathrm{I} \text {, followed by a second } \\
\text { dose administered four weeks } \\
\text { after the initial dose, with } \\
\text { subsequent doses given every } \\
\text { I } 2 \text { weeks thereafter }\end{array}$ & None & 2009 \\
\hline
\end{tabular}

Abbreviations: TNF, tumor necrosis factor- $\alpha$; RA, rheumatoid arthritis; JIA, juvenile idiopathic arthritis; SC, subcutaneous; mg, milligram; kg, kilogram; BIW, twice weekly; CD, Crohn's disease; EOW, every other week; UC, ulcerative colitis; IV, intravenous; IM, intramuscular. 


\section{Review of pharmacology and mode of action}

Th1 cells predominate in the skin and synovial fluid of psoriasis patients and give rise to pro-inflammatory cytokines TNF- $\alpha$, IFN- $\gamma$, and IL-2; all of which are major components that activate antigen-presenting cells and macrophages to induce T-cell activation. ${ }^{7,11,12}$ More recently, Th17 cells have been recognized as a distinct lineage of pro-inflammatory Th cells essential for the pathogenesis of autoimmune disease. $.^{13} \mathrm{IL}-1 \beta$ is required to activate a naïve T-cell down the Th17 pathway. In mice, commitment to the Th17 lineage is dependent on TGF- $\beta$, IL-6, and IL-23, resulting in Th17 cell expression of IL-6, IL-17, IL-21, IL-22, IFN- $\gamma$, chemokine ligand (CCL) 20, transcription factor ROR $\gamma$, and TNF- $\alpha$. IL-17 plays a critical role in epithelial defense, while IL-22 promotes epidermal hyperproliferation and keratinocyte proliferation and host defense proteins. ${ }^{14,15} \mathrm{Th} 1$ cells require IL-12 to support development, whereas Th17 cells depend on the presence of IL-23 to properly function. Many reports show that IL-12 and IL-23 play key roles in the development of psoriasis, in part due to their relation to both the stimulation of the innate and adaptive immune systems. In a mouse study, direct intradermal injections of IL-23 into normal skin produced erythematous, thick, scaly lesions that demonstrated a mixed dermal infiltrate and epidermal hyperplasia with associated with parakeratosis reminiscent of psoriatic plaques on histological analysis; although, injection with IL-12 in similar matter failed to induce the same response. ${ }^{16}$ The authors concluded that IL-23 is important in the development of psoriasis. Another study confirmed that IL-23 is an important cytokine is involved in the development of IL-17 producing Th17 cells. ${ }^{15}$ These authors showed that IL-22 is preferentially produced by Th17 cells and mediates the acanthosis induced by IL-23. It was concluded that Th17 cells, through the production of both IL-22 and IL-17, might have essential functions in host defense and in the pathogenesis of autoimmune diseases such as psoriasis. IL-22 appears to be a downstream mediator of psoriatic inflammation by mediating the communication between the immune system and epithelial cells. ${ }^{17} \mathrm{IL}-17$ is more pro-inflammatory, while IL-22 retards keratinocyte differentiation. IL-22 is also increased in psoriatic lesions and in plasma and these levels correlate with disease severity. ${ }^{18}$ Multiple reports have also implicated the IL-23 dependent IL-22, but not IL-17 production, in protective immunity to infection with gram-negative organisms such as Salmonella enteritidis in the respiratory and digestive epithelium. ${ }^{19-21}$ Recently, a Th22 cell subpopulation (characterized by the secretion of IL-22 and TNF- $\alpha$ ) was identified in the epidermis of individuals with psoriasis. ${ }^{22}$ Th22 clones derived from patients with psoriasis were stable in culture and exhibited a profile clearly separate from those of Th1, Th2, and Th17 cells. These pro-inflammatory Th22 responses were synergistically dependent on IL-22 and TNF- $\alpha$. The authors concluded that the human Th22 subset may represent a separate $\mathrm{T}$-cell division with a distinct identity with respect to gene expression and function, present within the epidermal layer in inflammatory skin diseases. Further, it was demonstrated that psoriasis mediators IL-17 and IL-22 synergistically induce the production of IL-20 subfamily proteins in cultured human keratinocytes and the expression of the IL-22 receptor (IL-22R) was also increased in epidermal lesions versus normal skin. ${ }^{23}$ IL-17 and IL-22 coordinately enhanced cytokine, chemokine, and growth factor production depending on the amount of IL-22R expression. The data concluded that increased IL-22R expression in epidermal keratinocytes contributes to the pathogenesis of psoriasis through enhancing the coordinated effects of IL-22 and IL-17.

Ustekinumab therapy rapidly decreased expression of a variety of pro-inflammatory cytokine genes in psoriatic skin lesions including p19, p40, and IL-17A. ${ }^{24}$ Recent evidence also suggests that efficacy from TNF- $\alpha$ antagonist therapy may be similar to the mechanism of ustekinumab by downregulating pro-inflammatory pathways in lesional skin. ${ }^{25,26}$ Etanercept reduced the inflammatory dendritic cell products that drive Th17 cell proliferation (IL-23), as well as Th17 cell products and downstream effector molecules (IL-17, IL-22, CCL 20, and beta-defensin 4). This study suggested a role for Th17 cells in addition to Th1 cells in the pathogenesis of psoriasis. Th17 cells may be particularly important in driving epidermal activation in psoriatic plaques, whereas Th1 cells must also be eliminated for final disease resolution.

It is suggested that certain genetic alteration of the IL-23 (p40 and p19) or IL-12 (p40 and p35) subunits as well as the IL-23 receptor or its ligand will lead to enhanced IL-23 production and subsequent psoriasis susceptibility. In contrast, other mutations that decrease IL-23 or IL-12 will give protection from psoriasis. ${ }^{27-29}$ Altogether, these findings indicate that genes participating in IL-12/23 signaling play a significant role in the pathogenesis of chronic epithelial inflammation as seen in psoriasis. In humans, IL-23 is clearly elevated in psoriatic lesions as indicated by increased levels of both p19 and p40 (subunits of IL-23) mRNA in lesional skin as compared to non-lesional skin, but the mRNA levels of p35 (subunit of IL-12) are not. ${ }^{30}$ These data suggest that IL-23 appears to play a more dominant role than IL-12 in psoriasis. 
Immunohistochemical analyses have revealed p40 and p19 (subunits of IL-23) protein expression in dermal dendritic cells and keratinocytes of lesional psoriatic skin. ${ }^{31,32}$ Genetic studies have shown that a single nucleotide polymorphism in p40 (the common subunit of both IL-12 and IL-23) ${ }^{33}$ as well as polymorphisms in the gene encoding $\mathrm{p} 19^{34}$ (IL-23 specific) was associated with the development of psoriasis.

IL-17A mRNA is elevated in psoriatic skin when compared to non-lesional skin $^{35}$ and immunohistochemical staining for IL-17A positive T-cells has also been reported. ${ }^{36}$ These authors concluded that human and mouse Th17 cells require distinct factors during differentiation and that human Th17 cells may regulate innate immunity in epithelial cells. IL-23 and IL-1 $\beta$ induced the development of human Th17 cells from naïve T-cells. IL-12 and IL-23 both share a common p40 subunit which is the target for the human monoclonal antibody ustekinumab. Ustekinumab does not associate with p35 subunit of IL-12 or the p19 subunit of IL-23, thus future medications may utilize these distinctions. This mechanism allows for the inhibition of naïve T-cells, which requires IL-12 and IL-23 for differentiation, proliferation, and effector function. Subsequently, both Th1 and Th17 cells and their pro-inflammatory cytokines are reduced resulting in marked efficacy and safety in the treatment of psoriasis. ${ }^{37}$

\section{Efficacy studies \\ Plaque psoriasis}

In early clinical studies on ustekinumab, confirmable results were seen after both intravenous and subcutaneous administration of the drug (Table 2). In the first-in-human, non-randomized, open-label study of intravenous doses of anti-IL-12/23, 18 subjects with at least 3\% body surface area involvement were enrolled in four dose groups $(0.1$, $0.3,1.0$, and $5.0 \mathrm{mg} / \mathrm{kg}$ ) to evaluate safety, efficacy, and pharmacokinetics. ${ }^{37}$ Twelve of 18 subjects (67\%) achieved at least a 75\% improvement in Psoriasis Area and Severity Index (PASI) between weeks 8 and 16 after study agent administration. Anti-IL-12 was well tolerated with no related serious adverse events or infusion reactions reported. The authors concluded that significant and sustained concentration-dependent improvement was observed in most subjects.

In another phase I study, the pharmacokinetics, pharmacodynamics, and clinical response of single subcutaneous administrations of anti-IL-12/23 was evaluated in 21 subjects. ${ }^{38}$ Subjects were enrolled sequentially into four dose cohorts $(0.27,0.675,1.35$, and $2.7 \mathrm{mg} / \mathrm{kg})$ and randomized to anti-IL-12/23 or placebo in a $4: 1$ ratio and evaluated through 24 weeks. Mostly mild adverse events and no serious adverse events were reported. Of the 17 subjects who received the IL-12/23 monoclonal antibody, 13 (76\%) achieved PASI 75, compared with no placebo subjects. mRNA expression of IL-12, IL-23, IL-8, IL-18, and IFN- $\gamma$ in psoriatic plaques decreased in subjects with sustained PASI improvement. ${ }^{1,7}$ The authors concluded that a single subcutaneous administration of IL-12/23 monoclonal antibody was well tolerated and showed excellent clinical response in subjects with moderate-to-severe psoriasis.

A double blind, placebo-controlled, phase II study further examined the role of ustekinumab in 320 patients with moderate-to-severe plaque psoriasis. ${ }^{39}$ Patients were assigned to receive ustekinumab at four varying subcutaneous dosages (one $45 \mathrm{mg}$ dose, one $90 \mathrm{mg}$ dose, four weekly $45 \mathrm{mg}$ doses, four weekly $90 \mathrm{mg}$ doses, or placebo). Patients were evaluated at weeks 12 and 24 for efficacy. Patients assigned to medication received one additional dose at week 16 if needed and those assigned to placebo crossed over to receive one $90 \mathrm{mg}$ dose at week 20. PASI 75 was achieved at week 12 in $52 \%$ of patients who received $45 \mathrm{mg}, 59 \%$ of those who received $90 \mathrm{mg}, 67 \%$ of those who received four weekly $45 \mathrm{mg}$ doses, and in $81 \%$ of those who received four weekly $90 \mathrm{mg}$ doses, as compared with $2 \%$ of those who received placebo. Strikingly, there were PASI 90 scores identified in $23 \%, 30 \%, 44 \%$, and $52 \%$ respectively, of patients who received the medication, as compared with $2 \%$ of patients who received placebo. PASI response rates correlated with the Physician's Global Assessment (PGA) scores. Further, as early as 2 weeks into therapy, notable improvements in psoriasis signs and symptoms were reported and patients experienced a significant improvement in quality of life scores. ${ }^{1,39}$

The longer-term efficacy and safety of ustekinumab has been evaluated in two major phase III studies in which treatment medication was compared with placebo. ${ }^{40,41}$ Both studies were powered to detect whether ustekinumab was more effective than placebo and all efficacy data were analyzed according to the assigned treatment group (intention-to-treat population [ITT]), while all the safety data were analyzed according to the actual treatment received. Previous biological therapy had been given to approximately half of the patients in PHOENIX 1 and approximately one third of patients in PHOENIX 2. The trial designs were complicated and consisted of 3 phases: 1) random assignment, where patients were dosed with placebo or treatment medication; 2) crossover, where patients initially assigned to placebo were then 


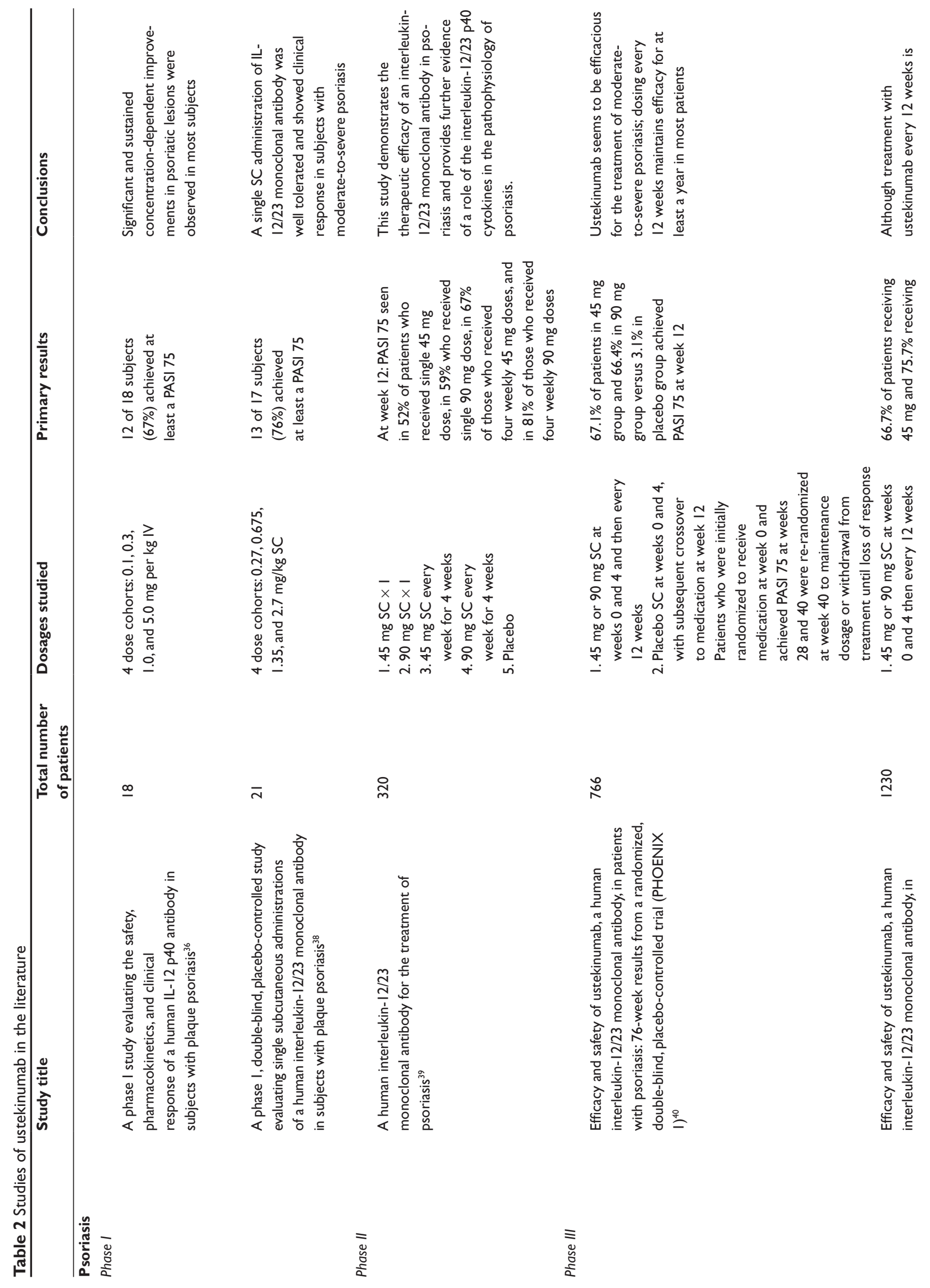



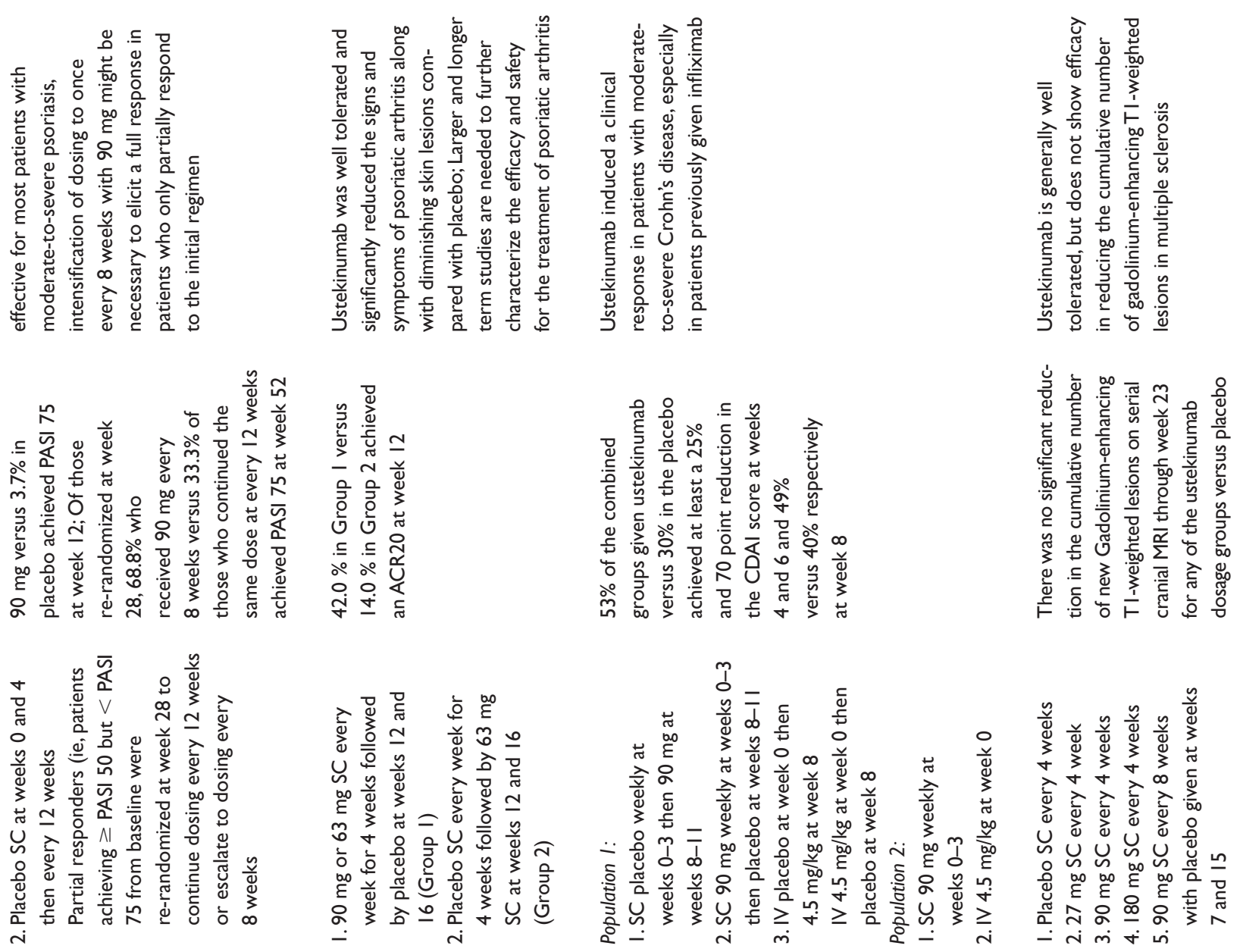

亭

$\stackrel{+}{\underline{a}}$

$\stackrel{d}{a}$
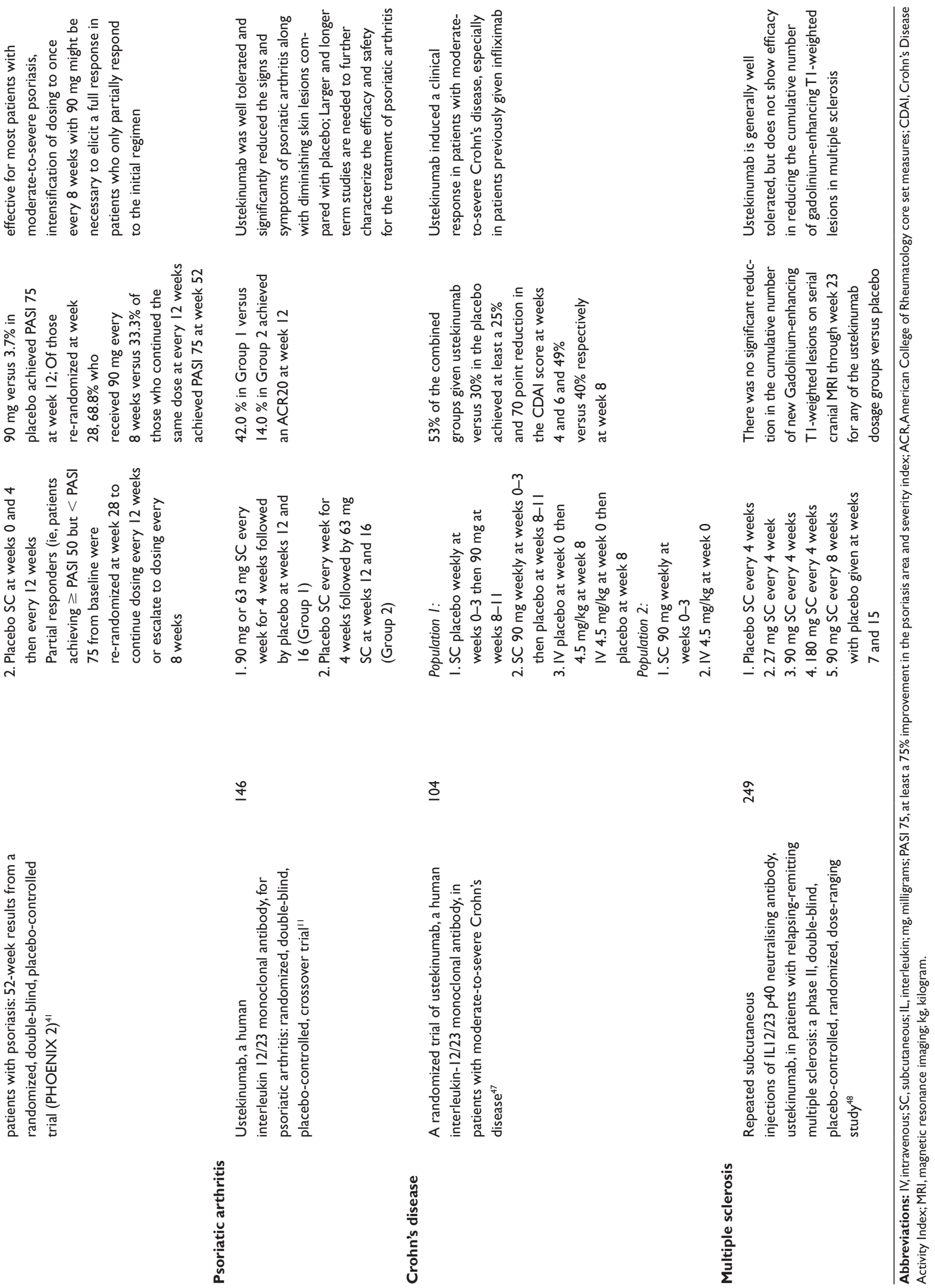
switched to treatment medication; and 3) re-randomization, where responders (PHOENIX 1) were re-randomized to active or placebo treatment or where partial responders (PHOENIX 2) were randomized to dose intensification (every 8 weeks) or continued treatment (every 12 weeks).

In PHOENIX 1, ${ }^{40} 766$ patients were randomized to receive subcutaneous injections of ustekinumab $45 \mathrm{mg}$ or $90 \mathrm{mg}$ at weeks 0 and 4, followed by the same dose every 12 weeks; or placebo at weeks 0 and 4 and then crossed over to receive ustekinumab $45 \mathrm{mg}$ or $90 \mathrm{mg}$ at weeks 12 and 16 , followed by dosing every 12 weeks. Patients who were originally randomized to ustekinumab and achieved a PASI 75 response at both weeks 28 and 40 were re-randomized at week 40 to maintenance ustekinumab or withdrawn from treatment (assigned to placebo) until loss of response (loss of at least 50\% PASI improvement). Patients not achieving PASI 75 at weeks 28 or 40 were not re-randomized and their dosing was discontinued or modified. Baseline randomization was stratified by investigational site, weight ( $\leq 90 \mathrm{~kg}$ or $>90 \mathrm{~kg}$ ), and the number of conventional systemic therapies to which patients had an inadequate response, intolerance, or contraindication ( $\leq 3$ or $>3$ ). Week 40 randomization was stratified by investigational site and baseline weight $(\leq 90 \mathrm{~kg}$ or $>90 \mathrm{~kg}$ ).

Significantly more patients in the ustekinumab treatment groups achieved the primary endpoint of a PASI 75 at week 12: $67.1 \%$ of patients receiving $45 \mathrm{mg}$ ustekinumab, $66.4 \%$ of patients receiving $90 \mathrm{mg}$ ustekinumab, and $3.1 \%$ of those receiving placebo (Figure 2). The onset of efficacy was rapid, with a higher proportion of patients in the ustekinumabtreated group achieving PASI 50 by week 2 and PASI 75 by week 4 . By week 12 , PASI 50 was achieved by $83.5 \%$ of patients receiving $45 \mathrm{mg}$ ustekinumab, $85.9 \%$ receiving $90 \mathrm{mg}$ ustekinumab, and $10.2 \%$ receiving placebo. Cleared (0) or minimal (1) disease based on the PGA was achieved in significantly more patients having active treatment $(60.4 \%$ in ustekinumab $45 \mathrm{mg}$ group, 61.7\% in ustekinumab $90 \mathrm{mg}$ group, and $3.9 \%$ in placebo group). Improvements in PASI scores were paralleled by the Dermatology Life Quality Index (DLQI), indicating that psoriasis improvement had a

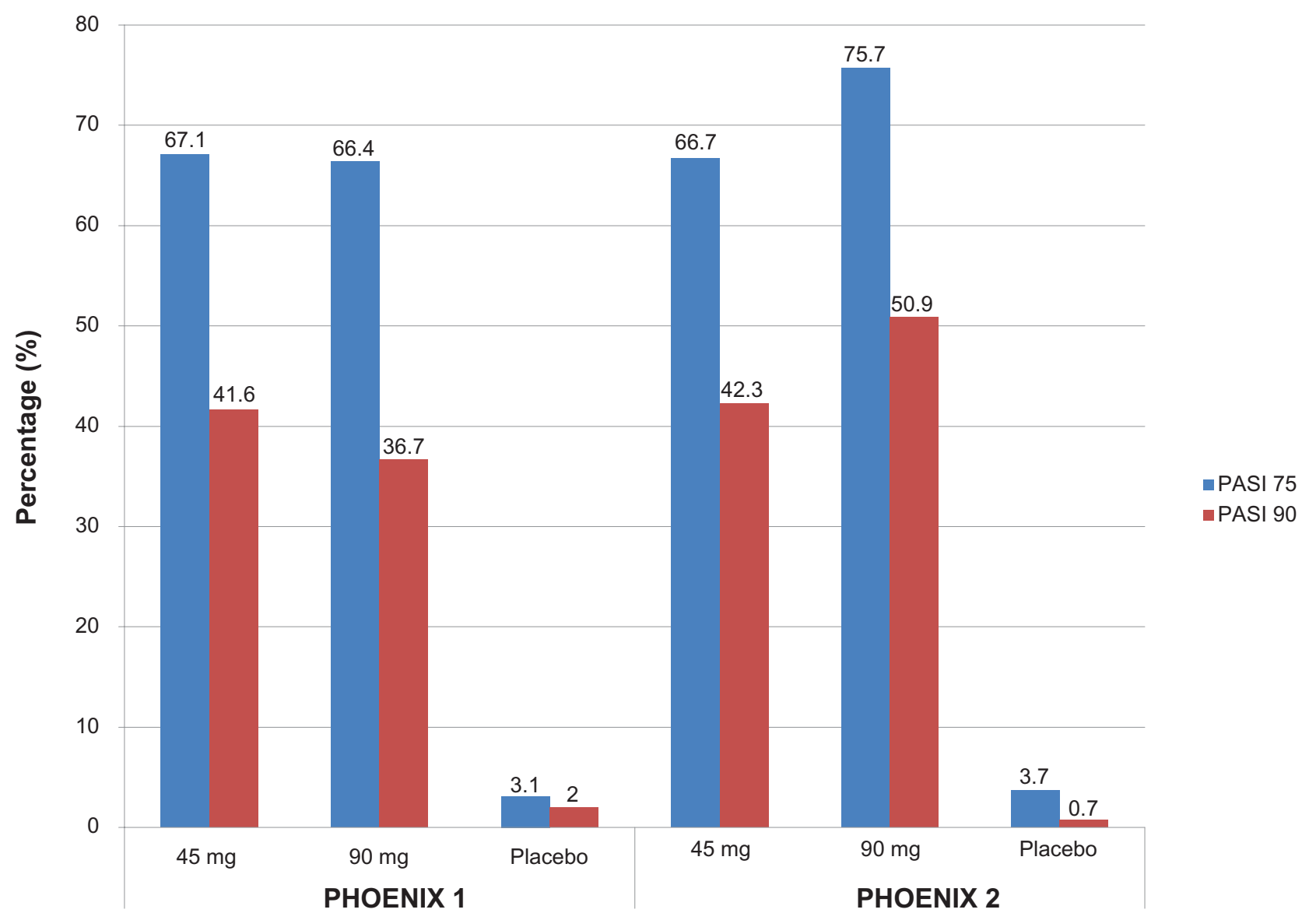

Figure 2 Efficacy of ustekinumab at week 12 in two clinical trials for moderate-to-severe psoriasis. $* P<0.000$ I versus placebo. 
positive effect on patient's quality of life. These values were maintained in patients in the treatment groups as opposed to the worsening scores seen in those withdrawn from treatment.

Enhanced efficacy was observed throughout the active treatment phase (after the placebo-controlled portion of the study), with a maximum effect noted at week 24 for both dosing groups (PASI 75 in $76.1 \%$ and $85.0 \%$ of the $45 \mathrm{mg}$ and $90 \mathrm{mg}$ groups respectively). Similar PASI values were noted in placebo subjects crossed over to ustekinumab treatment at week 12 . More than $90 \%$ of patients in both ustekinumab groups achieved PASI 50 and about half of patients in both ustekinumab groups achieved at least a PASI 90 at week 28 (Figure 3). Greatest responses were seen in patients who were originally allocated placebo and then randomized to ustekinumab $90 \mathrm{mg}$ and these responses were maintained through week 40.

Among patients re-randomized at week 40 to either treatment or placebo, maintenance of PASI 75 (ie, time to loss of PASI 75 response) was better in patients receiving maintenance therapy than in those withdrawn from therapy. PASI scores were steady through week 76 in the maintenance group, whereas the withdrawal group progressively has deterioration of PASI scores by week 44 (16 weeks after withdrawal) with acceleration of loss noted after week 52 . The median time to loss of PASI 75 after withdrawal was close to 15 weeks, with no reports of rebound psoriasis. The improvements declined from $96 \%$ at week 40 to about $40 \%$ at week 64 (about a 56\% loss). Upon re-initiating treatment (195 patients), 85.6\% regained PASI 75 within 12 weeks. The DLQI responses also worsened in patients withdrawn from therapy. Overall, PASI 75 response was better maintained to at least one year in those receiving maintenance ustekinumab than in those withdrawn from treatment at week 40. Adverse events were minimal, suggesting that treatment with ustekinumab was safe and effective for at least one year when administered every 12 weeks. In general, side effects did not require treatment adjustment, did not appear to be dose-related, and were not considered serious. Nonetheless, the size and duration of the trial do not rule out the potential

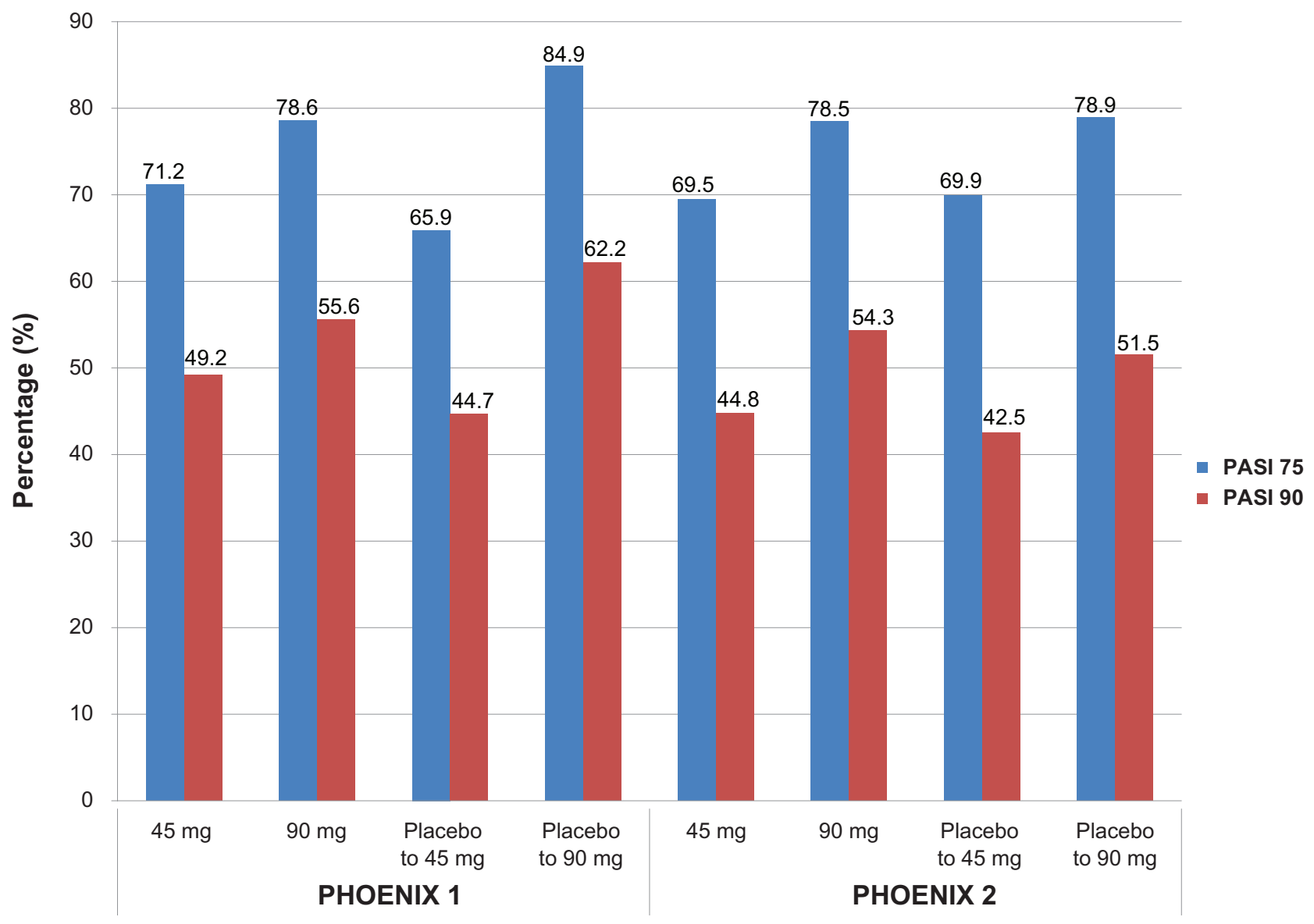

Figure 3 Efficacy of ustekinumab at week 28 in two clinical trials for moderate-to-severe psoriasis. 
for long-term, unforeseen side effects upon exposure of the medication to larger patient populations over longer durations.

In PHOENIX 2, ${ }^{41} 1230$ patients who were randomized to receive ustekinumab $45 \mathrm{mg}$ or $90 \mathrm{mg}$ at weeks 0,4 , and every 12 weeks, or placebo at weeks 0 and 4 with half randomized to crossover to receive ustekinumab $45 \mathrm{mg}$ and the other half to $90 \mathrm{mg}$ at weeks 12,16 , and every 12 weeks thereafter. Partial responders (patients achieving PASI $\geq 50$ but $\leq 75$ ) were re-randomized at week 28 to continue dosing every 12 weeks or escalate to dosing every 8 weeks. Patients not achieving PASI 50 at week 28 discontinued treatment and patients achieving PASI 75 at week 28 continued to receive the study drug every 12 weeks. The primary efficacy endpoint was the proportion of PASI 75 responders at week $12.66 .7 \%$ of patients receiving $45 \mathrm{mg}$ ustekinumab and $75.7 \%$ of patients receiving ustekinumab $90 \mathrm{mg}$ compared to $3.7 \%$ of patients receiving placebo achieved a PASI 75 response at week 12. A PGA of cleared (0) or minimal (1) psoriasis was seen in $68.0 \%$ of those treated with ustekinumab $45 \mathrm{mg}$ and $73.5 \%$ of those treated with $90 \mathrm{mg}$ compared with $4.9 \%$ of placebo, indicating a significant response in those treated with ustekinumab. Significant improvements in patient-reported outcomes based on decreases in the DLQI scores were seen in both ustekinumab groups. DLQI scores of 0 or 1 were seen in $55.3 \%$ and $56.4 \%$ of ustekinumab $45 \mathrm{mg}$ and $90 \mathrm{mg}$ groups respectively, compared to $3.2 \%$ on placebo. Efficacy was noted as early as week 2 (as measured by PASI 50) and most evident by week 4 (as measured by PASI 75). Interesting to note, at week 12 there were only few non-responders ( $<$ PASI 50): $16.4 \%$ of those receiving ustekinumab $45 \mathrm{mg}$ and $10.7 \%$ of those on ustekinumab $90 \mathrm{mg}$ compared to $90 \%$ of those taking placebo.

PASI 75 responses continued to increase after the placebo-controlled phase, with a maximum response noted at week 20 (74.9\% in ustekinumab $45 \mathrm{mg}$ group and 83.5\% in ustekinumab $90 \mathrm{mg}$ group). After cross over to active treatment, the response rates in the placebo to ustekinumab groups were similar to those seen in individuals originally randomized to ustekinumab. By week 28, PASI 75 rates were $69.5 \%$ to $78.5 \%$, while PASI 50 rates were over $92 \%$. Only $5 \%$ to $7 \%$ of all ustekinumab-treated patients attained less than a PASI 50 response. PGA was cleared (0) or minimal (1) in $61 \%$ to $70 \%$ of patients. The greatest response rate was seen in those patients switched from placebo to ustekinumab $90 \mathrm{mg}$, as also seen in PHOENIX 1.

Patients who were PASI 75 responders at week 28 continued to receive the study drug every 12 weeks until week 52, with all clinical responses sustained until week 52. At week 52, the median percent improvement from baseline in PASI was $95.3 \%$ in the $45 \mathrm{mg}$ group and $95.6 \%$ in the $90 \mathrm{mg}$ group. Partial responders at week 28 were seen in $22.7 \%$ of those treated with ustekinumab $45 \mathrm{mg}$ and $15.8 \%$ of those treated with ustekinumab $90 \mathrm{mg}$. These patients were more likely to have a higher body weight, more marked or severe disease as measured by PGA, have a higher incidence of psoriatic arthritis, and have a longer duration of psoriatic disease. More of the partial responders had used conventional systemic agents and were more likely to have failed treatment with at least on conventional systemic or biological agent than the responders. A higher percentage of partial responders $(12.7 \%)$ had neutralizing antibodies against ustekinumab than PASI 75 responders $(2.0 \%)$ and they were more likely to have lower (two to three times) ustekinumab serum levels than responders $(0.72 \mu \mathrm{g} / \mathrm{mL}$ in PASI 75 responders treated with $90 \mathrm{mg}$ ustekinumab versus $0.39 \mu \mathrm{g} / \mathrm{mL}$ in the $45 \mathrm{mg}$ ustekinumab group versus $0.14 \mu \mathrm{g} / \mathrm{mL}$ in partial responders) at week 28. A small proportion of partial responders were identified in the study where dose escalation from $90 \mathrm{mg}$ every 12 weeks to $90 \mathrm{mg}$ every 8 weeks led to significant improvement, nearly doubling the PASI 75 response rate (68.8\% versus $33.3 \%$ ) by week 52 . Although an improvement in response rate was not observed in partial responders who were escalated from $45 \mathrm{mg}$ every 12 weeks to $45 \mathrm{mg}$ every 8 weeks. Overall, partial responders at week 28 performed better when given dosages of $90 \mathrm{mg}$ every 8 weeks when compared to either $45 \mathrm{mg}$ frequency and/or dosing every 12 weeks. Dose intensification resulted in four to five times increase in mean trough serum drug concentrations in partial responders between weeks 28 and 52 (mean $0.70 \mu \mathrm{g} / \mathrm{mL}$ in the $45 \mathrm{mg}$ group, $1.45 \mu \mathrm{g} / \mathrm{mL}$ in the $90 \mathrm{mg}$ group). The conclusion was that ustekinumab at higher dosages $(90 \mathrm{mg}$ versus $45 \mathrm{mg}$ ) and for shorter intervals (8 weeks instead of 12 weeks) may be of benefit for patients who are partial responders. The efficacy data were obtained by non-responder imputation (NRI) analysis on the ITT population. This kind of analysis is considered a conservative method, so the outstanding long-term efficacy rates yielded by those studies could possibly be underestimation of the real potential of this IL-12 and IL-23 inhibitor. ${ }^{42}$

Adverse event reporting was not significantly different for patients treated with placebo or either of the ustekinumab doses. Upper respiratory tract infection, nasopharyngitis, headache, and arthralgias were the most common. During the placebo-controlled phase, the number of infections was similar between the all groups. Both studies documented 
improvement of overall skin response and quality of life in patients with both psoriasis and psoriatic arthritis. Throughout the studies, there were sustained improvements from baseline in the DLQI surveys in each group receiving ustekinumab compared with placebo.

The long-term side effects of ustekinumab are unknown and the majority of answers will come from post-marking studies and physician experience. Adverse events reported in clinical trials have been relatively mild, with the majority of events including susceptibility to mild infections such as nasopharyngitis and upper respiratory tract infection. Rates of infection were not higher in ustekinumab-treated patients when compared to placebo treated patients over 12 weeks of therapy. In the phase II trial, the frequency and character of adverse event rates were similar between the two groups; $79 \%$ of treated patients and $72 \%$ of placebo patients reported adverse events, while $43 \%$ in the treated group and 39\% in the placebo group reported minor infections. In the phase III studies, adverse events did not require discontinuation of therapy, although in real practice physicians may chose to hold dosing or discontinue therapy for a short time if a patient has recurrent or moderate-to-severe adverse events. In all ustekinumab studies, rates of serious infections, cardiovascular events, injection site reactions, and malignancies were low and the drug was well tolerated by patients. Serious adverse events in the ustekinumab group included 2 patients hospitalized for infections, 2 cases of myocardial infarction, 1 case of a cerebrovascular accident, 2 patients diagnosed with non-melanomatous skin cancer, and 1 case of prostate cancer. Interestingly, higher ustekinumab dosing did not appear to increase the infection rate in those treated. In the placebo group, 2 serious adverse events were reported: 1 case of basal cell carcinoma and 1 case of severe psoriasis exacerbation that required hospital admission.

PHOENIX 1 and 2 studies both demonstrate is the ustekinumab gives a rapid, clinically significant (measured by PASI, PGA, and quality of life scores) improvement in patients with moderate-to-severe psoriasis, including those who had failed prior biological or conventional systemic therapies. Clinical responses were apparent by 2 weeks, with maximal response rates seen after about 6 months. These data lend support to the notion that IL-12 and IL-23 have a key role in the pathogenesis of psoriasis. These clinically meaningful improvements were seen in patients treated with ustekinumab and were paralleled by improvements in patient-reported outcomes. Over $80 \%$ of patients receiving ustekinumab had a PASI 50 response at week 12 and over $90 \%$ of all patients had a PASI 50 at week 28 . The onset of action was seen within
2 weeks of the first medication dosage and was maintained in patients who continued treatment every 12 weeks for up to 76 weeks. The maintenance of efficacy between longer dosing intervals may be due to the fact that the pharmacodynamics effects of ustekinumab are longer than its pharmacokinetic effects. ${ }^{44}$ Further, the data suggest that a unique subset of partial responding patients could represent a distinct subset of patients who have key characteristics such as increased body weight, a longer history of psoriatic disease, have a history of psoriatic arthritis, and a greater resistance to biological agents. Symptoms gradually recurred in patients who therapy was withdrawn and quality of life improvements were lost, indicting the block of IL-12 and IL-23 is temporary and does not reverse the underlying causal mechanism of psoriasis. These observations suggest that maintaining response and quality of life improvements require continuous maintenance dosing. In patients withdrawn from ustekinumab, re-response could be restored with treatment within 12 weeks.

Partial responders represented a distinct subset of patients who had a higher body-weight, longer duration of psoriatic disease, had a history of psoriatic arthritis, and a greater resistance to biological and conventional systemic agents previously. Although this subpopulation had lower mean serum drug levels of ustekinumab than did patients who responded to treatment every 12 weeks, lower serum concentrations of ustekinumab alone do not completely explain their partial response. After dose intensification with $45 \mathrm{mg}$ in partial responders, trough drug concentrations were comparable with those achieved in the PASI 75 responders initially randomized to receive $90 \mathrm{mg}$; however, dose intensification in the $45 \mathrm{mg}$ group did not lead to an increase in clinical response. Thus, compared with responders, partial responders seemed to have disease that was more likely to be resistant to treatment. Nonetheless, this subpopulation does seem to have disease that is responsive to highest levels of ustekinumab, as evidenced by the dose intensification. These patients are more likely to respond to higher dosages $(90 \mathrm{mg}$ versus $45 \mathrm{mg}$ ) given more frequently (every 8 weeks versus every 12 weeks).

Ustekinumab was also studied in phase III multicenter, randomized, head-to-head study comparing ustekinumab and etanercept for the treatment of moderate-to-severe plaque psoriasis. ${ }^{44}$ Findings from this landmark study showed that ustekinumab demonstrated superior efficacy to etanercept in both primary (PASI 75 at week 12) and secondary (PGA score of cleared (0) or minimal (1) at week 12 and PASI 90 at week 12) efficacy endpoints. The ACCEPT trial included 903 patients $(3: 5: 5$ ratio; etanercept $=347$, ustekinumab 
$45 \mathrm{mg}=209$, ustekinumab $90 \mathrm{mg}=347$ ) with chronic plaque psoriasis. Patients were randomized to receive either ustekinumab $45 \mathrm{mg}$ or $90 \mathrm{mg}$ subcutaneously at weeks 0 and 4 or etanercept $50 \mathrm{mg}$ subcutaneously two times per week for 12 weeks. The primary endpoint of the trial was the percentage of patients achieving a PASI 75 at weeks 12. $68 \%$ and $74 \%$ of patients receiving ustekinumab $45 \mathrm{mg}$ or $90 \mathrm{mg}$ respectively achieved a PASI 75 , compared with $57 \%$ of patients receiving etanercept $50 \mathrm{mg}$ subcutaneous injections twice weekly for 12 weeks (Figure 4). A greater proportion of patients in the ustekinumab $45 \mathrm{mg}$ and $90 \mathrm{mg}$ groups achieved a PGA of cleared (0) or minimal (1) $(65 \%$ and $71 \%$, respectively) compared to $49 \%$ of etanercepttreated patients. PASI 90 was observed in $36 \%$ and $45 \%$ of patients in these respective ustekinumab groups versus $23 \%$ of etanercept-treated patients.

Among patients for whom conventional systemic psoriasis therapies were inadequate or intolerable, there were contraindications to their usage, a greater proportions of patients in the ustekinumab-treated groups achieved PASI 75 responses when compared with patients in the etanercept-treated group. In patients who had one previous treatment of systemic, biologic, or phototherapy, 68\% in the ustekinumab $45 \mathrm{mg}$ group and $74 \%$ of patients in the ustekinumab $90 \mathrm{mg}$ group achieved PASI 75, as compared to $57 \%$ of the etanercept group. In patients with two previous treatments, $67 \%$ of the $45 \mathrm{mg}$ group and $74 \%$ in the $90 \mathrm{mg}$ group achieved PASI 75, compared to $51 \%$ of the etanercept group. For those who had received three previous treatments, $55 \%$ of the $45 \mathrm{mg}$ group and $72 \%$ of the $90 \mathrm{mg}$ group reached PASI 75, compared to $39 \%$ in the etanercept group. Adverse events were experienced in less than $2 \%$ of patients receiving ustekinumab and included upper respiratory tract infection, arthralgia, headache, and infection (less than 1\% were deemed serious). Further, 4 malignancies were noted in the ustekinumab group ( 3 in the ustekinumab $45 \mathrm{mg}$ group and 1 in the ustekinumab $90 \mathrm{mg}$ group) compared to 0 in the etanercept-treated group. Injection site erythema was the most commonly reported event in the etanercept group $(14.7 \%)$ and occurred with a greater frequency than that observed in the ustekinumab groups (combined 0.7\%) and may have been influenced by the greater number of etanercept

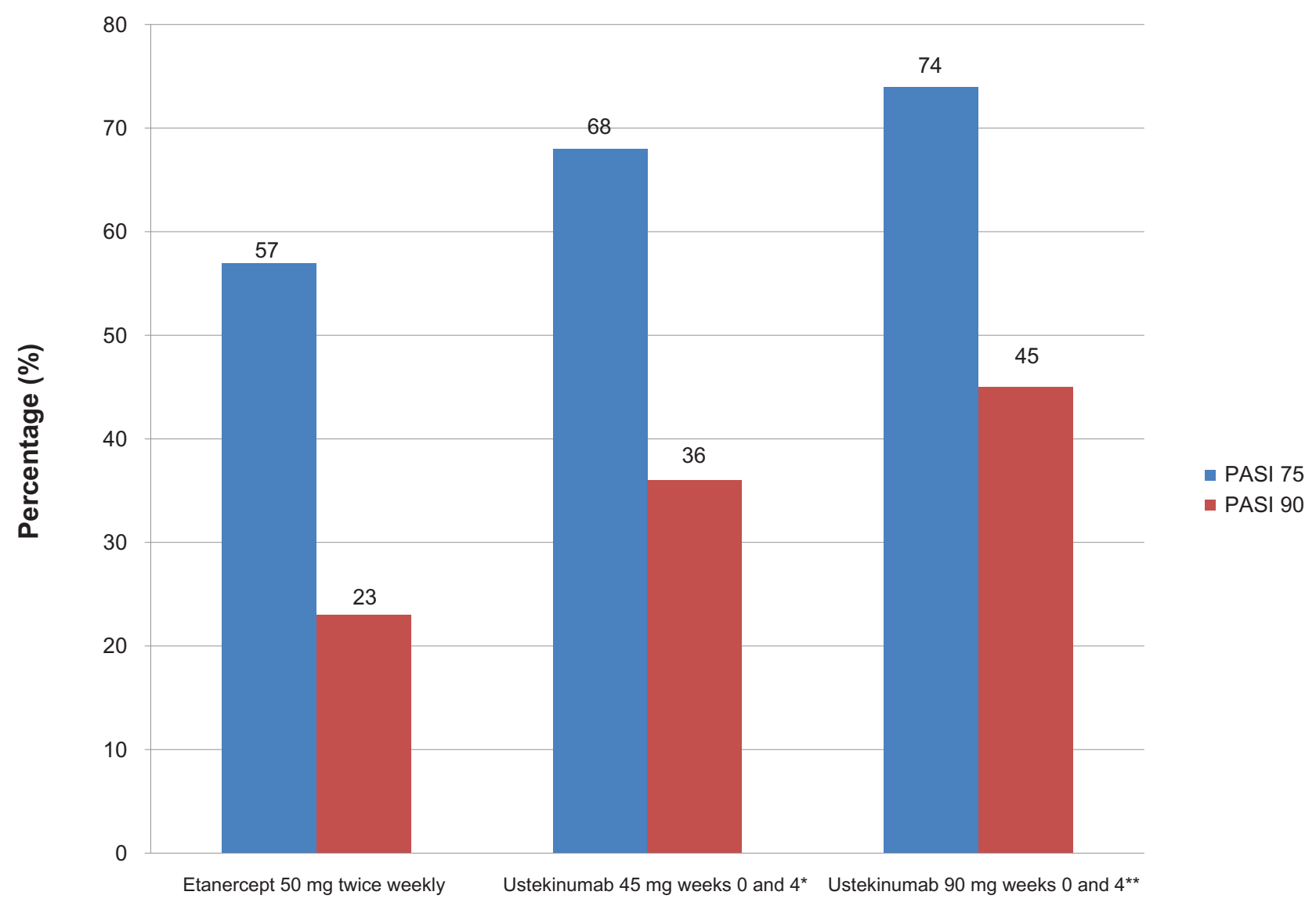

Figure 4 Week 12 data of a head-to-head comparison of etanercept and ustekinumab in psoriasis patients. $* P=0.012$ superiority versus etanercept; $* * P<0.001$ superiority versus etanercept. 
injections required (up to 48 in the 12-week study) compared with ustekinumab ( 2 injections).

The overwhelming conclusion was that patients with moderate-to-severe psoriasis treated with two doses of either $45 \mathrm{mg}$ or $90 \mathrm{mg}$ ustekinumab demonstrated superior response, as measured by PASI and PGA when compared with patients treated with etanercept twice weekly for 12 weeks. Additionally, ustekinumab and etanercept were generally well tolerated with comparable rates of adverse events. These data were presented as posters at the 17 th meeting of the European Academy of Dermatology and Venerology in Paris, France, in September 2008 and the 67th Annual Meeting of the American Academy of Dermatology in San Francisco, California, in March of 2009.

\section{Psoriatic arthritis}

Ustekinumab was shown to have modest clinical improvement in a phase II study in patients with psoriatic arthritis. ${ }^{11}$ This study was a double-blind, randomized, placebo-controlled, crossover study at 24 sites in North America and Europe. Patients with active psoriatic arthritis were randomly assigned to either: ustekinumab (90 mg or $63 \mathrm{mg}$ ) subcutaneous every week for 4 weeks (weeks 0-3) followed by placebo at weeks 12 and 16 (group 1); or placebo subcutaneous every week for 4 weeks (weeks 0-3) followed by ustekinumab (63 mg) at weeks 12 and 16 (group 2). The primary endpoint was a 20\% improvement in the American College of Rheumatology core set of measures (ACR20) at week 12. ACR20, ACR50, and ACR70 were determined in both groups at week 12. Groups 1 and 2 demonstrated: $42 \%$ versus $14 \%, 25 \%$ versus $7 \%$, and $11 \%$ versus $0 \%$ for the respective ACR scores. ACR20 was maintained by $36 \%$ of patients treated only with ustekinumab throughout the trial for up to 32 weeks. As well, PASI 75 was seen in $52 \%$ of those in group 1 versus $5 \%$ of those in group 2. During the placebo-controlled period (weeks 0-12), adverse events arose in $46(61 \%)$ patients in group 1 and 44 $(63 \%)$ in group 2 . Serious adverse events were recorded in $3(4 \%)$ group 2 patients and none $(0 \%)$ in group $1 ; 1$ case of myocardial infarction, 1 case of non-cardiac chest pain, and 1 case of hemorrhagic gastric ulcers. After week 12, 1 case of a hemorrhagic abdominal cyst was reported by a group 2 patient who had not received ustekinumab at weeks 12 and 16. Six other serious adverse events were reported through week 36 , including cases of syncope, respiratorytract infection, hemorrhage, stroke, myocardial infection, and gastric ulcer. One case of malignant basal cell cancer occurred in an individual who had been previously diagnosed with two basal cell cancers.
The authors concluded that ustekinumab significantly reduced signs and symptoms of psoriatic arthritis, diminished skin lesions compared with placebo, and was well tolerated. Larger and longer term phase III studies are needed to definitively establish safety and efficacy in this population of patients. Nonetheless, results from this study are promising and suggest that treatment with ustekinumab can remain safe and effective for a long duration as well as maintain improvements in physical function and quality of life.

\section{Crohn's disease}

Crohn's disease is an inflammatory condition of the bowel that is believed to be the result of an imbalance between proinflammatory and anti-inflammatory mediators.

Unpredictable flares and remissions characterize the longterm course of this illness. Conventional therapy includes systemic corticosteroids and other immunosuppressive medications such as azathioprine, methotrexate, or mycophenolate mofetil, anti-inflammatory medications such as sulfasalazine and mesalamine, and/or systemic antibiotics such as metronidazole and fluoroquinolones. A large number of patients may still experience active disease and require biological medications (eg, infliximab, adalimumab, and certolizumab pegol) for treatment as TNF- $\alpha$, a key inflammatory cytokine and mediator of intestinal inflammation, is expressed prominently in inflammatory bowel disease. However, some patients may experience a primary nonresponse or become intolerant to treatment. Thus, alternative treatments are needed for more safe and effective management of inflammatory bowel disease.

IL-12/23 has also been implicated in the pathophysiology of Crohn's disease; however the complex relationship between Th1 and Th17 cells has not been completely analyzed. ${ }^{45}$ It is thought that IL-23 may play important roles in controlling the differential of Th1/Th17 balance in both ulcerative colitis and crohn's disease, although Th17 cells seem to exist in both diseases. ${ }^{46}$ Thus, ustekinumab was studied in a double-blind, cross-over trial of 104 patients with moderate-to-severe Crohn's disease. ${ }^{47}$ Patients were randomly assigned to one of four groups: 1) subcutaneous placebo weekly at weeks 0-3 then $90 \mathrm{mg}$ at weeks $8-11$; 2) subcutaneous $90 \mathrm{mg}$ weekly at weeks $0-3$ then placebo at weeks $8-11 ; 3$ ) intravenous placebo at week 0 then $4.5 \mathrm{mg} / \mathrm{kg}$ at week 8 ; or 4) intravenous $4.5 \mathrm{mg} / \mathrm{kg}$ at week 0 then placebo at week 8 . Clinical response rates for the combined groups given ustekinumab and placebo were $53 \%$ and $30 \%$ respectively at weeks 4 and 6 , and $49 \%$ and $40 \%$ respectively at week 8 . In a subgroup of 49 patients who were previously given infliximab (neither 
primary nor secondary non-responders), clinical response to ustekinumab was significantly greater than the group given placebo through week 8 . Overall, there were higher frequencies of clinical response, remission, and symptom improvements observed in those who received intravenous injections versus subcutaneous injections.

In the second part of this study, an open-label trial assessed the effects of four weekly subcutaneous injections of ustekinumab (90 mg weekly at weeks $0-3$ ) versus one intravenous infusion of ustekinumab $(4.5 \mathrm{mg} / \mathrm{kg}$ at week 0 ) in 27 patients who were either primary or gradual non-responders to infliximab. It was found that within this subgroup, patients treated with ustekinumab rather than placebo achieved higher clinical response rates. Clinical responses at week 8 to subcutaneous and intravenous ustekinumab were $43 \%$ and $54 \%$ respectively. Additionally, higher response and remission rates were observed with intravenous ustekinumab injections versus subcutaneous injections. There was no increase in the number of adverse or serious adverse events in patients given ustekinumab through week 8 compared with placebo. Overall, the placebo group experienced higher incidences of nausea, fatigue, and disease exacerbation while the treatment group experienced anxiety and pruritus. Adverse events such as pyrexia, flushing, and pruritus occurring under intravenous administration were mild and reported by $19 \%$ of ustekinumab patients and $0 \%$ of those receiving placebo. The rates of infections were similar between both treatment and placebo groups. Two serious infections occurred throughout the course of the trial: one case of disseminated histoplasmosis in a patient previously treated with infliximab concurrently taking immunosuppressants and one case of viral gastroenteritis. Reported administration site reactions were mild and seen most commonly in patients receiving subcutaneous placebo (4\%) compared patients receiving subcutaneous ustekinumab $(0 \%)$.

The authors concluded that ustekinumab induced a clinical response in patients with moderate-to-severe Crohn's disease, especially in patients previously given infliximab.

\section{Relapsing/remitting multiple sclerosis (RRMS)}

Multiple sclerosis is a complex neurological disorder of the central nervous system, characterized by recurrent and multifocal inflammation, demyelination, and axonal damage. The clinical manifestations include loss of visual, sensorimotor, autonomic, and cognitive functions. Current available treatments are modestly effective (eg, IFN- $\beta$ and glatiramer acetate) or are intolerable long-term (eg, mitoxantrone and natalizumab). ${ }^{48}$ IL-12/23 have been strongly implicated in the pathogenesis of multiple sclerosis ${ }^{49}$ and in experimental autoimmune encephalomyelitis, an autoimmune disease which serves as a model for multiple sclerosis. ${ }^{50,51}$

Repeated subcutaneous injections of ustekinumab were tested in a recent study assessing safety, efficacy, and pharmacokinetics in patients with RRMS. In this phase II, multicentered, randomized, double-blind, placebo-controlled study, 249 patients with RRMS, patients were eligible to be equally and randomly assigned (based on study site and presence or absence of gadolinium-enhancing T1-weighted lesions at baseline) to one of five groups that received placebo or four different ustekinumab dosages at weeks $0-3,7,11,15$, and 19. Ustekinumab doses were: 1) placebo subcutaneous every 4 weeks; 2) $27 \mathrm{mg}$ subcutaneous every 4 weeks; 3) $90 \mathrm{mg}$ subcutaneous every 4 weeks; 4) $90 \mathrm{mg}$ subcutaneous every 8 weeks; 5) $180 \mathrm{mg}$ subcutaneous every 4 weeks. The $90 \mathrm{mg}$ subcutaneous every 8 weeks group received placebo substitute at weeks 7 and 15. The primary endpoint was the cumulative number of new gadolinium-enhancing T1-weighted lesions on serial cranial magnetic resonance imaging (MRI) through week 23 and patients were followed up through week 37. Ustekinumab treatment did not show a significant reduction in the primary endpoint for any dosage groups versus placebo. Due to the lack of demonstrated efficacy of ustekinumab in RRMS, the study was halted after week 37. At week 37, adverse events occurred in 38 (78\%) placebo-treated patients and 170 (85\%) ustekinumab-treated patients, with infections most commonly reported. Mild upper respiratory tract infections and nasopharyngitis were most commonly reported by approximately $50 \%$ of both placebo and ustekinumab groups. Headache, fatigue, and injection-site reactions were slightly higher in frequency among patients treated with ustekinumab (32\%) versus placebo (14\%). Serious adverse events occurred in one (2\%) placebo-treated patient and six (3\%) ustekinumab-treated patients; among those reported were flank pain, tonsil cancer, colon cancer, dyspnea, and rotator cuff syndrome. Malignant diseases were reported in two patients shortly after the initiation of ustekinumab treatment; both patients were withdrawn from the trial and given appropriate treatment, which resulted in complete remission. The patient diagnosed with tonsil cancer had a history of smoking and was diagnosed with localized squamous cell carcinoma at week 20 . The patient with colon cancer had progressive anemia which lead to a diagnosis of adenocarcinoma of the colon at week 16. No serious infections, cardiovascular events, or exacerbation of demyelinating events occurred. This study demonstrated that the use of an IL-12/23 neutralizing 
antibody did not reveal therapeutic efficacy or inhibit the formation of inflammatory white matter lesions in patients with RRMS. ${ }^{52}$ Although evidence from animal models supports the role of ustekinumab in the pathogenesis of autoimmune demylenating disease, therapeutic efficacy in this controlled clinical trial was not confirmed.

\section{Safety and tolerability}

The safety and tolerability of ustekinumab over several years is quite exceptional, although the long-term safety, efficacy, and tolerability remain to be determined. As of now, it appears as ustekinumab is safe and effective for short-term use in patients with Th1 and Th17 mediated conditions such as those described. More targeted therapies (eg, monoclonal antibody targeting of cytokines) for inflammatory conditions appear (at this time) to have a better safety profiles compared to those traditional therapies which globally suppress the immune system and can predispose patients to organ toxicity, infections, and cancers. Nonetheless, few long-term safety data on biological agents can refute or support these claims.

Insight into the safety of the therapeutic targeting of particular cytokines comes from other diseases or genetic defects. Patients with hyper-IgE syndrome (Job's syndrome) have been shown to have defects in Th17 cells (which produce IL-17 and -22), but not Th1 cells (which produce IFN- $\gamma$ ). These patients are prone to chronic Staphylococcus aureus abscesses, chronic candidiasis, and pulmonary infections. ${ }^{53-55}$ IL-12 and Th1 cells are important in fighting infections as those with defects in p40 or in the IL-12 receptor subunit, IL-12R $\beta 1$, are susceptible to intracellular bacterial infections like those caused by mycobacterial and $S$. enteriditis. ${ }^{56,57}$ A large homozygous deletion within the IL-12p40 subunit gene was found in a child with bacille Calmette-Guérin (BCG) and S. enteritidis infection, precluding expression of functional IL-12p70 cytokine by activated dendritic cells and phagocytes. As a result, IFN- $\gamma$ production by lymphocytes was markedly impaired. This was the first discovered human disease resulting from a cytokine gene defect suggesting that IL-12 is essential to and appears specific for protective immunity to intracellular bacteria such as mycobacteria and Salmonella. ${ }^{58}$ Subsequently, this was supported by experimental infections of knockout mice lacking IL-12 or the IL-12 receptor and it was determined that IL-12, the signature IFN- $\gamma$-inducing cytokine, was crucial for protective immunity against intracellular microorganisms. ${ }^{59}$

Many individuals with genetic defects of IL-12/23-IFN- $\gamma$ axis signal transduction, have been reported to have impaired ability to produce IFN- $\gamma$, an essential component of the Th1 cytokine pathway which is responsible for clearing infections and intracellular bacteria. ${ }^{60}$ This transduction pathway has two major components, an IL-12/23 axis and an IFN- $\gamma$ axis, that result in cellular activation to aid in the elimination of intracellular pathogens. ${ }^{61}$ An assortment of hypotheses are postulated regarding the mechanisms that invariably lead to susceptibility to mycobacteria and Salmonella infection such: 1) that IL-12 and IL-23 can induce TNF- $\alpha$ and granulocyte-macrophage colony-stimulating factor (GMCSF) which can modulate INF- $\gamma$-independent activity; 2) that IL-12 and -23 have autocrine function on antigen-presenting cells (APCs) which may have an additive effect on cytokine production and thus microbicidal mechanisms; and 3 ) that IL-17, the production of with is stimulated by IL-23, but inhibited by IL-12 dependent immune mechanisms and is known to mediate inflammatory responses and play a role in the pathogenesis of various autoimmune disorders, function may be impaired. In summary, these mechanisms unanimously suggest that IL-12/23 defects may skew the Th1/ Th2 signal transduction pathways important in protecting (and controlling) against various infectious agents; although future longitudinal studies will be needed to distinguish between these possibilities to delineate the role of IL-12 and IL-23 versus IFN- $\gamma$ production in the resistance of various infectious etiologies. These disease-causing mutations of the IL-12/23-IFN- $\gamma$ circuit were initially thought to be rare, but have now been reported in over 200 patients in a multitude of countries worldwide since $1996 .{ }^{62}$

Patients diagnosed with latent tuberculosis upon screening were allowed into the phase III ustekinumab trials as long as they had received appropriate anti-tuberculous therapy. Thus far, no cases of tuberculosis, atypical mycobacterial, or Salmonella infections have been reported in patients treated with anti-IL12/23 antibodies. Nonetheless, as with other biological therapies, patients with a history of tuberculosis or those with latent disease should be closely monitored with yearly tuberculous skin testing, IFN- $\gamma$ release assays, and/or chest X-ray and pulmonary referral when appropriate. ${ }^{63,64}$ Moreover, prior to treatment with anti-IL-12/23 therapy, patients with active or latent tuberculosis should be treated with appropriate anti-tuberculous therapy as the risk of tuberculous infections and the targeting of pro-inflammatory cytokines have not been completely elucidated. Further, the role of anti-IL-12/23 therapy in the development of malignancies is not yet known and will be an important issue to discuss in the future. There is some evidence that IL-12 has anti-tumor activity as the 
systemic administration of IL-12 in mice leads to anti-tumor activity ${ }^{7,65}$ and IL-23 may promote tumor formation. ${ }^{5}$ Lastly, while ustekinumab did not help in inhibiting RRMS, it is noteworthy that it did not create any neurological events as other biological agents, such as anti-TNF- $\alpha$ therapies, have been associated with new onset or exacerbation of central nervous system demyelinating disorders (some presenting with mental status changes and some associated with permanent disability) such as transverse myelitis, optic neuritis, and multiple sclerosis, as well as cases of new onset or exacerbation of seizure disorders. One case of reversible posterior leukoencephalopathy syndrome (RPLS) was observed in 3523 ustekinumab-treated subjects. RPLS is a neurological disorder, which is not caused by demyelination or a known infectious agent and can present with headache, seizures, confusion, and visual disturbances. Conditions with which it has been associated include preeclampsia, eclampsia, acute hypertension, cytotoxic agents, and immunosuppressive therapy. The subject, who had received 12 doses of ustekinumab over approximately two years, presented with headache, seizures, and confusion. No additional ustekinumab injections were administered and the subject fully recovered with appropriate treatment.

\section{Patient-focused perspectives}

As demonstrated, the clinical data suggest that ustekinumab is a safe and effective agent in the short-term treatment of psoriasis and possibly other inflammatory conditions driven by the IL-12/23 pathways. In trials thus far, patients experienced significant improvements in skin disease and symptoms, modest improvement in joint involvement, and sustained improvements quality of life and health assessment disability scores. ${ }^{66}$ Ustekinumab shows phamarcokinetic first-order elimination with a pharmacokinetic behavior typical of an IgG1-based monoclonal antibody and has a half-life of 3 weeks. This supports the infrequent dosing of every 12 weeks in patients with psoriasis. ${ }^{67}$ Infrequent dosing schedules, ease of administration, and long-term remissions make these newer monoclonal antibodies convenient and economical treatments options. The findings of the PHOENIX studies, suggest that ustekinumab can provide a new, highly effective and safe therapy for the treatment of moderate-to-severe psoriasis. Treatment with 2 subcutaneous injections of ustekinumab, followed by an injection every 12 weeks, led to PASI 75 response in about three-quarters of patients, irrespective of dose. As approved, ustekinumab is dosed subcutaneously at weeks 0 and 4 and then every 12 weeks thereafter at a dosage of $45 \mathrm{mg}$ per injection for patients $\leq 100 \mathrm{~kg}(220 \mathrm{lb})$ and
$90 \mathrm{mg}$ per injection for patients $>100 \mathrm{~kg}(220 \mathrm{lb})$. In subjects weighing $>100 \mathrm{~kg}(220 \mathrm{lb}), 45 \mathrm{mg}$ was also shown to be efficacious, however, $90 \mathrm{mg}$ resulted in greater efficacy. ${ }^{68}$ The convenience of such infrequent dosing could positively affect adherence in psoriasis patients, who have historically shown poor adherence and low patient satisfaction. Dosing flexibility up to $90 \mathrm{mg}$ every 8 weeks might benefit the subgroup of patients who have treatment-resistant disease, while minimizing unnecessary drug exposure in the overall population.

Additionally, unlike the TNF- $\alpha$ blocking agents, the safety profile of ustekinumab as late does not limit its use in patients with a history of neurological disorders (such central nervous system demyelinating disorders), autoimmune conditions, heart failure, or history of malignances (such as lymphoma), making it particularly unique. There have been few reports of serious infections such as bacterial, mycobacterial, invasive fungal, viral, or other opportunistic pathogens such as tuberculosis, histoplasmosis, aspergillosis, candidiasis, coccidioidomycosis, listeriosis, and pneumocystosis, as has been seen more commonly in patients on TNF- $\alpha$ blocking agents (typically with the concurrent use of methotrexate and/or systemic corticosteroids). Nonetheless, close clinical monitoring with laboratory testing should be performed. Ustekinumab treatment has been associated with infections requiring hospitalization such as cellulitis, diverticulitis, osteomyelitis, gastroenteritis, pneumonia, and urinary tract infections. Patients deficient in IL-12/23 or defects of their pathway receptors have shown susceptibility to infections such as mycobacterium, Salmonella, and BCG vaccinations, thus routine diagnostic testing should be performed and dictated by close clinical monitoring. Finally, ustekinumab is an immunosuppressant and theoretically has the ability to increase the risk of malignancies, although the safety of ustekinumab has not been evaluated in patients who have a history of malignancy or who have a known malignancy and the decision to do so should be proceeded with caution. Published literature showed that administration of murine IL-12 caused an antitumor effect in mice that contained transplanted tumors and IL-12/23p40 knockout mice or mice treated with antiIL-12/23p40 antibody had decreased host defense to tumors. Mice genetically manipulated to be deficient in both IL-12 and IL-23 or IL-12 alone developed UV-induced skin cancers earlier and more frequently compared to wild-type mice. ${ }^{69,70}$ The relevance of these experimental findings in mouse models for malignancy risk in humans is unknown, although these findings may have future implications when 
concomitantly treating a patient with phototherapy and anti-IL12/23 therapy. Further studies and poster-marketing surveillance will help to determine the longer-term safety of ustekinumab and other similar medications approaching (eg, briakinumab, formerly ABT-874).

\section{Conclusions}

Ustekinumab is a monoclonal antibody directed against the common p40 subunit of both IL-12 and IL-23 that has demonstrated superior efficacy and safety in the treatment of psoriasis. Evidence suggests that T-cell mediated inflammatory conditions are influenced by IL-12 and IL-23 resulting in skin disease secondary to a dysregulation of the immune system. Medications that suppress all or part of the immune system have a profound therapeutic effect as demonstrated by this novel anti-cytokine targeted therapy. As more is learned about the pathogenesis of T-cell mediated skin conditions, targeted therapies that selectively block the pathogenic inflammatory pathways will offer advanced treatments for patients suffering with severe disease. Biological agents propose safe and effective alternatives to the traditional systemic therapies, although they are not without side-effects and the long-term safety and efficacy are not known. Supplementary investigations will be required to substantiate the full role of these therapies in the longerterm treatment of T-cell mediated inflammatory conditions. Although we all agree on the need of more effective and safe therapies, we need to be cautious as there are many examples of therapies that were approved because of good evidence of efficacy and safety during clinical trials and then needed to be retired from the market because of serious side effects (eg, rofecoxib, efalizumab). For the time being, the excitement for ustekinumab and immunologically targeted therapies is well justified and offers new options for a diversity of patients.

\section{Disclosures}

Members of Dr Lebwohl's department own patents on short-contact tazarotene, topical genistein, and use of the excimer laser for vitiligo.

Dr Lebwohl's conflicts of interest are

\begin{tabular}{lll}
\hline Company name & Relationship & Compensation \\
\hline Abbott Laboratories & $\mathrm{A}, \mathrm{S}$ & $\mathrm{H}$ \\
Amgen & $\mathrm{A}, \mathrm{S}$ & $\mathrm{H}$ \\
Astellas & $\mathrm{A}, \mathrm{S}$ & $\mathrm{H}$ \\
Centocor & $\mathrm{A}, \mathrm{S}$ & $\mathrm{H}$ \\
DermiPsor & $\mathrm{C}$ & $\mathrm{H}$ \\
\hline
\end{tabular}

(Continued)

\begin{tabular}{lll}
\hline Company name & Relationship & Compensation \\
\hline Galderma & A, S & H \\
Genentech & A, S & H \\
GlaxoSmithKline & A, S & H \\
Graceway & C & H \\
Incyte & O & H \\
Magen Biosciences & C & H \\
Medicis & A & H \\
NeoStrata & C & H \\
Novartis & A, S & H \\
Nycomed & A & H \\
Pfizer & A & H \\
Pharmaderm & C & H \\
Sanofi-Aventis & C & H \\
Stiefel & A, S & H \\
Taro & C & H \\
Triax & A, S & H \\
Warner Chilcott & A, S & H \\
\hline
\end{tabular}

Relationship: $\mathrm{A}=$ Advisory Board; $\mathrm{C}=$ Consultant; $\mathrm{S}=$ Speaker; $\mathrm{O}=$ Other Compensation: $\mathrm{H}=$ Honoraria

Dr Emer is an investigator for Centocor.

\section{References}

1. Rozenblit M, Lebwohl M. New biologics for psoriasis and psoriatic arthritis. Dermatol Ther. 2009;22(1):56-60.

2. Bilac C, Ermertcan AT, Bilac DB, Deveci A, Horasan GD. The relationship between symptoms and patient characteristics among psoriasis patients. Indian J Dermatol Venereol Leprol. 2009;75(5):551.

3. Van Voorhees AS, Fried R. Depression and quality of life in psoriasis. Postgrad Med. 2009;121(4):154-161.

4. National Psoriasis Foundation. http://www.psoriasis.org/netcommunity/ learn_statistics. Accessed Dec 19, 2009.

5. Tesmer LA, Lundy SK, Sarkar S, Fox DA. Th17 cells in human disease. Immunol Rev. 2008;223:87-113.

6. Murphy KM, Reiner SL. The lineage decisions of helper T cells. Nat Rev Immunol. 2002;2(12):933-944.

7. Chien AL, Elder JT, Ellis CN. Ustekinumab: a new option in psoriasis therapy. Drugs. 2009;69(9):1141-1152.

8. Oppmann B, Lesley R, Blom B, et al. Novel p19 protein engages IL-12p40 to form a cytokine, IL-23, with biological activities similar as well as distinct from IL-12. Immunity. 2000;13(5):715-725.

9. Stockinger B, Veldhoen M. Differentiation and function of Th17 T cells. Curr Opin Immunol. 2007;19(3):281-286.

10. Harrington LE, Hatton RD, Mangan PR, et al. Interleukin 17producing $\mathrm{CD}^{+}$effector $\mathrm{T}$ cells develop via a lineage distinct from the T helper type 1 and 2 lineages. Nat Immunol. 2005 Nov; 6(11): $1123-1132$.

11. Gottlieb A, Menter A, Mendelsohn A, et al. Ustekinumab, a human interleukin 12/23 monoclonal antibody, for psoriatic arthritis: randomised, double-blind, placebo-controlled, crossover trial. Lancet. 2009;373(9664):633-640.

12. Cuchacovich RS, Espinoza LR. Ustekinumab for psoriatic arthritis. Lancet. 2009;373(9664):605-606.

13. Asarch A, Barak O, Loo DS, Gottlieb AB. Th17 cells: a new therapeutic target in inflammatory dermatoses. $J$ Dermatolog Treat. 2008;19(6):318-326.

14. Zheng Y, Valdez PA, Danilenko DM, et al. Interleukin-22 mediates early host defense against attaching and effacing bacterial pathogens. Nat Med. 2008;14(3):282-289. 
15. Zheng Y, Danilenko DM, Valdez $P$, et al. Interleukin-22, a $\mathrm{T}(\mathrm{H}) 17$ cytokine, mediates IL-23-induced dermal inflammation and acanthosis. Nature. 2007;445(7128):648-651.

16. Chan JR, Blumenschein W, Murphy E, et al. IL-23 stimulates epidermal hyperplasia via TNF and IL-20R2-dependent mechanisms with implications for psoriasis pathogenesis. J Exp Med. 2006;203(12): 2577-2587.

17. Nograles KE, Zaba LC, Guttman-Yassky E, et al. Th17 cytokines interleukin (IL)-17 and IL-22 modulate distinct inflammatory and keratinocyteresponse pathways. Br J Dermatol. 2008;159(5):1092-1102.

18. Wolk K, Witte E, Wallace E, et al. IL-22 regulates the expression of genes responsible for antimicrobial defense, cellular differentiation, and mobility in keratinocytes: a potential role in psoriasis. Eur J Immunol. 2006;36(5):1309-1323.

19. Siegemund S, Schütze N, Schulz S, et al. Differential IL-23 requirement for IL-22 and IL-17A production during innate immunity against Salmonella enterica serovar Enteritidis. Int Immunol. 2009;21(5): 555-565.

20. Schulz SM, Köhler G, Schütze N, et al. Protective immunity to systemic infection with attenuated Salmonella enterica serovar enteritidis in the absence of IL-12 is associated with IL-23-dependent IL-22, but not IL-17. J Immunol. 2008;181(11):7891-7901.

21. Godinez I, Raffatellu M, Chu H, et al. Interleukin-23 orchestrates mucosal responses to Salmonella enterica serotype Typhimurium in the intestine. Infect Immun. 2009;77(1):387-398.

22. Eyerich S, Eyerich K, Pennino D, et al. Th22 cells represent a distinct human $\mathrm{T}$ cell subset involved in epidermal immunity and remodeling. J Clin Invest. 2009;119(12):3573-3585.

23. Tohyama M, Hanakawa Y, Shirakata Y, et al. IL-17 and IL-22 mediate IL-20 subfamily cytokine production in cultured keratinocytes via increased IL-22 receptor expression. Eur J Immunol. 2009;39(10): 2779-2788

24. Toichi E, Torres G, McCormick TS, et al. An anti-IL-12p40 antibody down-regulates type 1 cytokines, chemokines, and IL-12/IL-23 in psoriasis. J Immunol. 2006 1;177(7):4917-4926.

25. Gottlieb AB, Chamian F, Masud S, et al. TNF inhibition rapidly downregulates multiple proinflammatory pathways in psoriasis plaques. J Immunol. 2005; 175(4):2721-2729.

26. Zaba LC, Cardinale I, Gilleaudeau P, et al. Amelioration of epidermal hyperplasia by TNF inhibition is associated with reduced Th17 responses. J Exp Med. 2007;204(13):3183-3194.

27. Cargill M, Schrodi SJ, Chang M, et al. A large-scale genetic association study confirms IL12B and leads to the identification of IL23R as psoriasis-risk genes. Am J Hum Genet. 2007;80(2):273-290.

28. Capon F, Di Meglio P, Szaub J, et al. Sequence variants in the genes for the interleukin-23 receptor (IL23R) and its ligand (IL12B) confer protection against psoriasis. Hum Genet. 2007;122(2):201-206.

29. Nair RP, Ruether A, Stuart PE, et al. Polymorphisms of the IL12B and IL23R genes are associated with psoriasis. J Invest Dermatol. 2008;128(7):1653-1661.

30. Chen X, Tan Z, Yue Q, Liu H, Liu Z, Li J. The expression of interleukin23 (p19/p40) and inteleukin-12 (p35/p40) in psoriasis skin. J Huazhong Univ Sci Technolog Med Sci. 2006;26(6):750-752.

31. Piskin G, Sylva-Steenland RM, Bos JD, Teunissen MB. In vitro and in situ expression of IL-23 by keratinocytes in healthy skin and psoriasis lesions: enhanced expression in psoriatic skin. J Immunol. 2006;176(3):1908-1915.

32. Lee E, Trepicchio WL, Oestreicher JL, et al. Increased expression of interleukin 23 p19 and p40 in lesional skin of patients with psoriasis vulgaris. J Exp Med. 2004;199(1):125-130.

33. Tsunemi Y, Saeki H, Nakamura K, et al. Interleukin-12 p40 gene (IL12B) 3'-untranslated region polymorphism is associated with susceptibility to atopic dermatitis and psoriasis vulgaris. J Dermatol Sci. 2002;30(2):161-166.

34. Nair RP, Duffin KC, Helms C, et al. Genome-wide scan reveals association of psoriasis with IL-23 and NF-kappaB pathways. Nat Genet. 2009;41(2):199-204.
35. Wilson NJ, Boniface K, Chan JR, et al. Development, cytokine profile and function of human interleukin 17-producing helper T cells. Nat Immunol. 2007;8(9):950-957.

36. Kauffman CL, Aria N, Toichi E, et al. A phase I study evaluating the safety, pharmacokinetics, and clinical response of a human IL-12 p40 antibody in subjects with plaque psoriasis. J Invest Dermatol. 2004;123(6):1037-1044.

37. Sobell JM, Kalb RE, Weinberg JM. Management of moderate to severe plaque psoriasis (part 2): clinical update on T-cell modulators and investigational agents. J Drugs Dermatol. 2009;8(3):230-238.

38. Gottlieb AB, Cooper KD, McCormick TS, et al. A phase 1, double-blind, placebo-controlled study evaluating single subcutaneous administrations of a human interleukin-12/23 monoclonal antibody in subjects with plaque psoriasis. Curr Med Res Opin. 2007;23(5):1081-1092.

39. Krueger GG, Langley RG, Leonardi C, et al. A human interleukin-12/23 monoclonal antibody for the treatment of psoriasis. $N$ Engl J Med. 2007;356(6):580-592.

40. Leonardi CL, Kimball AB, Papp KA, et al. Efficacy and safety of ustekinumab, a human interleukin-12/23 monoclonal antibody, in patients with psoriasis: 76-week results from a randomised, double-blind, placebo-controlled trial (PHOENIX 1). Lancet. 2008;371(9625):1665-1674.

41. Papp KA, Langley RG, Lebwohl M, et al. Efficacy and safety of ustekinumab, a human interleukin-12/23 monoclonal antibody, in patients with psoriasis: 52-week results from a randomised, double-blind, placebo-controlled trial (PHOENIX 2). Lancet. 2008;371(9625):16751684.

42. Alwawi EA, Krulig E, Gordon KB. Long-term efficacy of biologics in the treatment of psoriasis: what do we really know? Dermatol Ther. 2009;22(5):431-440.

43. Zhu Y, Hu C, Lu M, et al. Population pharmacokinetic modeling of ustekinumab, a human monoclonal antibody targeting IL-12/23p40, in patients with moderate to severe plaque psoriasis. J Clin Pharmacol. 2009;49(2):162-175.

44. Griffiths CEM, Strober B, Fidelus-Gort R, Menter A. A Phase 3, Multicenter, Randomized Study Comparing Ustekinumab and Etanercept for the Treatment of Moderate to Severe Plaque Psoriasis. P3318. 2009 AAD meeting, San Francisco.

45. Brand S. Crohn's disease: Th1, Th17 or both? The change of a paradigm: new immunological and genetic insights implicate Th17 cells in the pathogenesis of Crohn's disease. Gut. 2009;58(8):1152-1167.

46. Kobayashi T, Okamoto S, Hisamatsu T, et al. IL23 differentially regulates the Th1/Th17 balance in ulcerative colitis and Crohn's disease. Gut. 2008;57(12):1682-1689.

47. Sandborn WJ, Feagan BG, Fedorak RN, et al. A randomized trial of Ustekinumab, a human interleukin-12/23 monoclonal antibody, in patients with moderate-to-severe Crohn's disease. Gastroenterology. 2008;135(4):1130-1141.

48. Segal BM, Constantinescu CS, Raychaudhuri A, et al. Repeated subcutaneous injections of IL12/23 p40 neutralising antibody, ustekinumab, in patients with relapsing-remitting multiple sclerosis: a phase II, double-blind, placebo-controlled, randomised, dose-ranging study. Lancet Neurol. 2008;7(9):796-804.

49. Cua DJ, Sherlock J, Chen Y, et al. Interleukin-23 rather than interleukin12 is the critical cytokine for autoimmune inflammation of the brain. Nature. 2003;421(6924):744-748.

50. Touil T, Fitzgerald D, Zhang GX, Rostami AM, Gran B. Pathophysiology of interleukin-23 in experimental autoimmune encephalomyelitis. Drug News Perspect. 2006;19(2):77-83.

51. Segal BM, Dwyer BK, Shevach EM. An interleukin (IL)-10/IL-12 immunoregulatory circuit controls susceptibility to autoimmune disease. J Exp Med. 1998;187(4):537-546.

52. Longbrake EE, Racke MK. Why did IL-12/IL-23 antibody therapy fail in multiple sclerosis? Expert Rev Neurother. 2009;9(3):319-321.

53. Ma CS, Chew GY, Simpson N, et al. Deficiency of Th17 cells in hyper IgE syndrome due to mutations in STAT3. J Exp Med. 2008;205(7):1551-1557. 
54. Milner JD, Brenchley JM, Laurence A, et al. Impaired T(H)17 cell differentiation in subjects with autosomal dominant hyper-IgE syndrome. Nature. 2008;452(7188):773-776.

55. Grimbacher B, Holland SM, Gallin JI, et al. Hyper-IgE syndrome with recurrent infections--an autosomal dominant multisystem disorder. N Engl J Med. 1999;340(9):692-702.

56. de Jong R, Altare F, Haagen IA, et al. Severe mycobacterial and Salmonella infections in interleukin-12 receptor-deficient patients. Science. 1998;280(5368):1435-1438.

57. Altare F, Durandy A, Lammas D, et al. Impairment of mycobacterial immunity in human interleukin-12 receptor deficiency. Science. 1998;280(5368):1432-1435.

58. Altare F, Lammas D, Revy P, et al. Inherited interleukin 12 deficiency in a child with bacille Calmette-Guérin and Salmonella enteritidis disseminated infection. J Clin Invest. 1998;102(12):2035-2040.

59. Fieschi C, Casanova JL. The role of interleukin-12 in human infectious diseases: only a faint signature. Eur J Immunol. 2003;33(6):1461-1464.

60. Esther van de Vosse, Ottenhoff TH. Human host genetic factors in mycobacterial and Salmonella infection: lessons from single gene disorders in IL-12/IL-23-dependent signaling that affect innate and adaptive immunity. Microbes Infect. 2006;8(4):1167-1173.

61. MacLennan C, Fieschi C, Lammas DA, et al. Interleukin (IL)-12 and IL-23 are key cytokines for immunity against Salmonella in humans. J Infect Dis. 2004;190(10):1755-1757.

62. Filipe-Santos O, Bustamante J, Chapgier A, et al. Inborn errors of IL-12/23- and IFN-gamma-mediated immunity: molecular, cellular, and clinical features. Semin Immunol. 2006;18(6):347-361.

63. Lebwohl M, Bagel J, Gelfand JM, et al. From the Medical Board of the National Psoriasis Foundation: monitoring and vaccinations in patients treated with biologics for psoriasis. J Am Acad Dermatol. 2008;58(1):94-105.
64. Doherty SD, Van Voorhees A, Lebwohl MG, et al. National Psoriasis Foundation consensus statement on screening for latent tuberculosis infection in patients with psoriasis treated with systemic and biologic agents. J Am Acad Dermatol. 2008;59(2):209-217.

65. Weiss JM, Subleski JJ, Wigginton JM, Wiltrout RH. Immunotherapy of cancer by IL-12-based cytokine combinations. Expert Opin Biol Ther. 2007;7(11):1705-1721.

66. Lebwohl M, Papp K, Han C, et al. Ustekinumab improves health-related quality of life in patients with moderate-to-severe psoriasis: results from the PHOENIX 1 trial. Br J Dermatol. 2009 Nov 9. [Epub ahead of print]

67. Zhou H, Hu C, Zhu Y, et al. Population-based exposure-efficacy modeling of ustekinumab in patients with moderate to severe plaque psoriasis. J Clin Pharmacol. 2009 Nov 23 [Epub ahead of print].

68. Stelara ${ }^{\text {тм }}$ (ustekinumab) [package insert]. http://www.stelarainfo. com/stelarainfo/assets/pdf/PrescribingInformation.pdf. Accessed Oct 1, 2009

69. Maeda A, Schneider SW, Kojima M, Beissert S, Schwarz T, Schwarz A. Enhanced photocarcinogenesis in interleukin-12-deficient mice. Cancer Res. 2006;66(6):2962-2969.

70. Meeran SM, Mantena SK, Meleth S, Elmets CA, Katiyar SK. Interleukin-12-deficient mice are at greater risk of UV radiation-induced skin tumors and malignant transformation of papillomas to carcinomas. Mol Cancer Ther. 2006;5(4):825-832.

71. Enbrel ${ }^{\circledR}$ (etanercept) [package insert]. http://www.enbrel.com/pdf/ enbrel_pi.pdf. Accessed Oct 12, 2009.

72. Humira ${ }^{\circledR}$ (adalimumab) [package insert]. http://www.rxabbott.com/pdf/ humira.pdf. Accessed Oct 1, 2009.

73. Remicade ${ }^{\circledR}$ (infliximab) [package insert]. http://www.remicade.com/ remicade/assets/HCP_PPI.pdf. Accessed Oct 12, 2009.

74. Amevive ${ }^{\circledR}$ (alefacept) [package insert] http://www.astellas.us/docs/ amevive.pdf. Accessed Oct 12, 2009.
Therapeutics and Clinical Risk Management

\section{Publish your work in this journal}

Therapeutics and Clinical Risk Management is an international, peerreviewed journal of clinical therapeutics and risk management, focusing on concise rapid reporting of clinical studies in all therapeutic areas, outcomes, safety, and programs for the effective, safe, and sustained use of medicines. This journal is indexed on PubMed Central, CAS,

\section{Dovepress}

EMBase, Scopus and the Elsevier Bibliographic databases. The manuscript management system is completely online and includes a very quick and fair peer-review system, which is all easy to use. Visit http://www.dovepress.com/testimonials.php to read real quotes from published authors. 